\title{
Mechanisms of physical-biological-biogeochemical interaction at the oceanic mesoscale
}

\author{
Dennis J. McGillicuddy, Jr. \\ Department of Applied Ocean Physics and Engineering \\ Woods Hole Oceanographic Institution \\ Woods Hole, MA 02543, USA. \\ Email:dmcgillicuddy@whoi.edu \\ Manuscript submitted to Annual Review of Marine Science \\ March 31, 2015
}


Table of Contents

Abstract 3

Key words 3

1. INTRODUCTION

2. A NEW WINDOW INTO PHYSICAL-BIOLOGICAL INTERACTIONS AT THE

34 MESOSCALE: ANALYSIS IN EDDY-CENTRIC COORDINATES 5

35 3. SURVEY OF MECHANISMS BY WHICH EDDIES AFFECT UPPER OCEAN

36 CHLOROPHYLL DISTRIBUTIONS

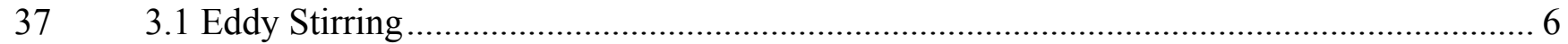

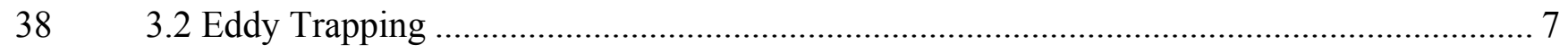

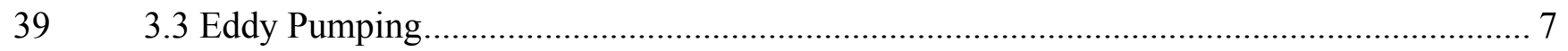

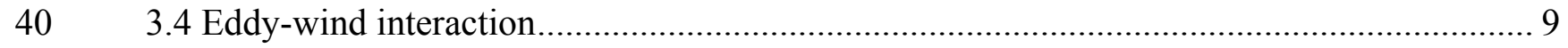

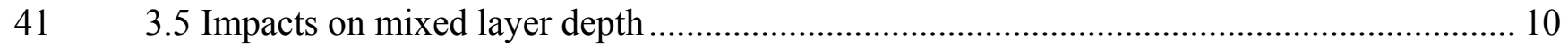

$42 \quad 3.6$ Mechanisms of CHL enhancement in the peripheries of anticyclonic eddies .................... 10

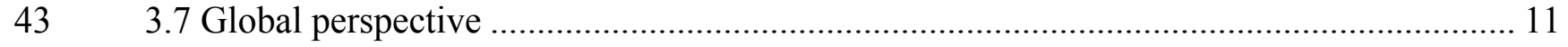

44 4. EDDY IMPACTS ON MEAN PROPERTIES AND FLUXES …….................................. 12

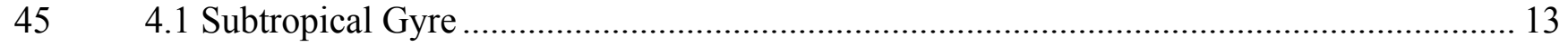

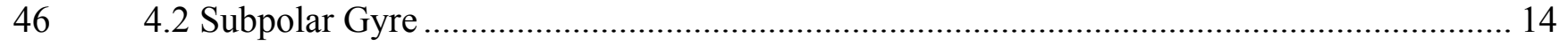

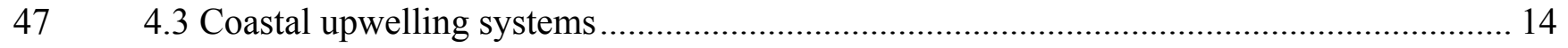

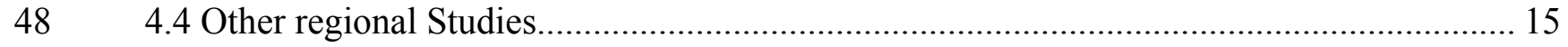

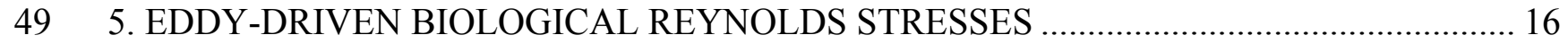

50 6. INFLUENCES ON PHYTOPLANKTON COMMUNITY COMPOSITION AND

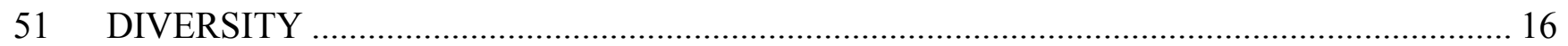

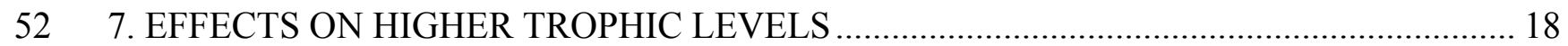

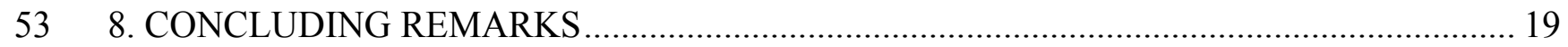

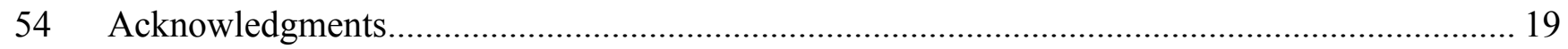




\begin{abstract}
Mesoscale phenomena are ubiquitous and highly energetic features of ocean circulation.

60 Their influence on biological and biogeochemical processes varies widely, stemming from not

61 only advective transport but also through generation of environmental variations that affect

62 biological and chemical rates. Elucidation of the attendant mechanisms of physical-biological-

63 biogeochemical interaction is made difficult by the ephemeral nature of the underlying

64 processes, necessitating the use of multidisciplinary approaches involving in situ observations,

65 remote sensing, and modeling. All three aspects are woven through this review in an attempt to

66 synthesize current understanding of the topic, with particular emphasis on novel developments in
\end{abstract}

67 recent years.

Key words

74

Eddies, eddy pumping, advection, eddy-wind interaction, eddy-driven stratification, plankton

76 diversity. 
Interconnection among the physics, biology, and biogeochemistry of the sea stems from three basic sources. First, the rates of biological and chemical reactions depend on environmental parameters such as temperature, salinity, nutrient concentration, etc. Second, hydrodynamic transport continually redistributes dissolved and suspended constituents in the water column. Third, constituents of interest can have directed motion through the water as a result of buoyancy (sinking or floating) and behavior (swimming) in the case of motile organisms. Each of these three aspects supports a variety of mechanisms creating biological and biogeochemical variability at a wide range of space and time scales. For example, the difference in deep water nutrient concentrations between the North Atlantic and North Pacific basins has been attributed to the joint effects of the global overturning circulation and remineralization of sinking particulate material (Broecker \& Peng 1982).

A particularly strong manifestation of physical-biological-biogeochemical interactions takes place at the oceanic mesoscale. The currents, fronts, and eddies that comprise this class of phenomena occur on spatial scales of tens to hundreds of kilometers, and are in many ways dynamically analogous to atmospheric weather. Mesoscale motions are typically produced by instability processes that result in flow features that are in approximate geostrophic balance in the horizontal and hydrostatic balance in the vertical; they are characterized by small Rossby and Froude numbers, as well as small aspect ratios. Of course the mesoscale occurs within a continuum of scales, bounded above by the large scale that sets the mean gradients from which eddies are generated, and bounded below by the submesoscale, in which motions are also significantly influenced by rotation and stratification but ageostrophic effects play a primary role in the balance of forces. Although the dynamics of mesoscale eddies and fronts are closely related, we will focus here mostly on the former. For a recent review on the nature and consequences of oceanic eddies from a primarily physical point of view, see McWilliams (2008).

Targeted studies of the biological impacts of mesoscale eddies date back at least as far as the late 1970s and early 1980s (Supplementary Table). Pingree et al. (1979) pioneered interdisciplinary investigations of eddies in shelf seas. Some of the first synoptic maps of phytoplankton, primary production, and seston in the open ocean were collected during the POLYMODE program, providing evidence of eddy-driven variations in all of these quantities (Radchenko 1983, Roukhiyainen \& Yunev 1983). At about that same time, advances in remote sensing yielded the first satellite-based estimates of chlorophyll, indicating a variance spectrum consistent with geostrophic turbulence (Gower et al. 1980). Detailed interdisciplinary process studies of Gulf Stream Rings began in that same era, focusing on eddy-induced variability and regional impacts (Ring Group 1981). These developments led to advancements in the conceptual basis for mesoscale physical-biological interactions (Legendre \& Demers 1984, Mackas et al. 1985, Woods 1988). Interest in the large-scale integrated impacts of eddies on ocean biogeochemistry was stimulated by the apparent discrepancy between estimates of new production and nutrient supply through vertical mixing (Jenkins \& Goldman 1985, Shulenberger \& Reid 1981). Specifically, mesoscale processes were hypothesized to be responsible for the "missing" nutrients in the subtropical gyre (Jenkins 1988a). While debate on that topic has continued through the present time, several new aspects have emerged - including the question of whether eddies constitute a net sink of nutrients in the subpolar gyre (McGillicuddy et al. 2003) and in coastal upwelling regions (Gruber et al. 2011).

This review is an attempt to synthesize our understanding of mesoscale physicalbiological-biogeochemical interactions, with particular emphasis on progress over the last 15 
years. One new development during this time period is the analysis of both data and models in "eddy-centric" coordinates to illuminate the underlying dynamics; this approach is described in section 2. This framework is used in section 3 as a basis to survey the mechanisms by which eddies can influence upper ocean distributions of chlorophyll. Eddy impacts on mean properties and fluxes are reviewed in section 4, followed by descriptions of three relatively new and growing areas of inquiry: eddy-driven biological Reynolds stresses (section 5), controls on community composition and diversity (section 6), and mesoscale niche utilization by higher trophic levels (section 7). Concluding remarks are provided in section 8. This work builds on earlier reviews by Angel and Fasham (1983), Flierl and McGillicuddy (2002), Lewis (2002), Lévy (2008), Oschlies (2008), Klein and Lapeyre (2009), Williams and Follows (2011; see Chapter 9). Mahadevan (2016) reviews submesoscale biological and biogeochemical dynamics.

\section{A NEW WINDOW INTO PHYSICAL-BIOLOGICAL INTERACTIONS AT THE MESOSCALE: ANALYSIS IN EDDY-CENTRIC COORDINATES}

Recent progress in automated methods for identifying and tracking mesoscale eddies with satellite altimetry has facilitated construction of a global atlas of eddy trajectories, amplitudes, and sizes (Figure 1) (Chelton et al. 2011b). Use of the derived eddy-centric coordinates to merge altimetric sea surface height ( $\mathrm{SSH}$ ) data with other remotely sensed properties such as satellite ocean color (CHL), sea surface temperature (SST), and ocean vector winds is now providing unprecedented opportunities for investigation of the physical and biological dynamics of mesoscale phenomena. Construction of eddy-centric composites of many (in some cases, thousands) of synoptic realizations of satellite data has allowed mean eddy-driven signals to emerge. These coherent eddy-driven structures in physical and biological properties vary regionally, reflecting a variety of different mechanisms by which mesoscale dynamics can influence upper ocean CHL distributions (Gaube et al. 2014).

A key initial finding from the eddy-centric analysis of satellite-derived SSH was the degree of nonlinearity of mid-ocean eddies. Whereas earlier assessments of the westward propagating signal in SSH based on a single altimeter were attributed to linear Rossby wave dynamics (Chelton \& Schlax 1996), higher resolution data products from multiple satellite missions merged together (Pascual et al. 2006) yielded a different picture. Chelton et al. (2007) computed a nonlinearity parameter from the ratio of the altimetrically-inferred geostrophic swirl velocity (u) to the propagation speed I of each eddy feature, finding that the vast majority of eddies were nonlinear $(u / c>1)$. This finding has key implications with respect to interpretation of the associated biological signal: nonlinear eddies trap fluid inside them, whereas linearly propagating wavelike disturbances do not.

Initial investigations of the relationships between satellite-based SSH and CHL revealed coherence in large-scale westward propagating signals that were attributed to linear Rossby waves (Cipollini et al. 2001, Uz et al. 2001), analogous to the Chelton and Schlax (1996) assessment of westward propagating signals in SSH alone. A variety of mechanisms were proposed to explain the observed coherence in SSH and CHL, including (a) lateral advection of the mean chlorophyll gradient, (b) uplift of the deep chlorophyll maximum into the surface layer, (c) enhancement of phytoplankton biomass stimulated by upwelling of nutrients, and (d) accumulation of material in convergence zones within the planetary wave field (Charria 2003, Dandonneau et al. 2003, Killworth et al. 2004). These early studies focused on large-scale signals characteristic of Rossby waves by processing the satellite measurements with scale- 
selective filters, and in some cases (Killworth et al. 2004) by utilizing only a single altimeter and thus a lower-resolution data set.

Using the new global data base of eddy trajectories, Chelton et al. (2011a) overlaid eddy tracks on the westward-propagating signals previously attributed to Rossby waves in the filtered $\mathrm{SSH}$ and ocean color data (Figure 2d,e). Coincidence of those features strongly suggests eddies are driving the variations. How might eddies be aliased into a larger-scale Rossby wave signal? Westward propagation of both types of features stems from latitudinal dependence of the effects of earth's rotation, causing them to translate at approximately the same speed. In essence, a patchwork of westward propagating eddies has a zonal wavenumber-frequency spectrum that is qualitatively similar to that expected for linear Rossby waves, which explains why eddies can pass through the filters intended to eliminate them in earlier studies (McGillicuddy 2011).

These findings require reassessment of the underlying mechanisms used to explain satellite observations of variability in SSH and upper ocean chlorophyll. Although the same four basic processes of biomass modulation (a-d) mentioned above remain valid, their expression takes different dynamical forms at various scales, ranging from the mesoscale down to the submesoscale (Abraham 1998, Lévy et al. 2001, Siegel et al. 2008). In the next section we survey the various mechanisms, focusing on the mesoscale.

\section{SURVEY OF MECHANISMS BY WHICH EDDIES AFFECT UPPER OCEAN CHLOROPHYLL DISTRIBUTIONS}

\subsection{Eddy Stirring}

Turbulent advection by mesoscale and submesoscale flows has long been recognized as a source of phytoplankton patchiness in the ocean (see review by Martin (2003)). Idealized models of two-dimensional geophysical flows reveal the cascade of variance from large to small scales via stirring of the populations (Abraham 1998), although in some instances biological dynamics can dominate (Srokosz et al. 2003). Direct observational evidence of mesoscale stirring has been derived from remotely sensed synoptic snapshots of surface geostrophic velocity (from altimetry) and chlorophyll (Lehahn et al. 2007). Advanced algorithms for diagnosing various phytoplankton functional types has facilitated investigation of stirring effects on fluid dynamical niches (d'Ovidio et al. 2010).

From an eddy-centric perspective, rotational flow will tend to perturb the local CHL distribution via azimuthal advection. Consider, for example, a clockwise-rotating eddy (northern hemisphere anticyclone) in a northward CHL gradient, shown schematically in Figure 2a (top). The western (leading) edge of the eddy contains a negative CHL anomaly in the northwest quadrant and the eastern (trailing) edge a positive CHL anomaly in the southeast quadrant. In the same background field, a counterclockwise-rotating eddy (northern hemisphere cyclone) will result in a positive anomaly in the southwest quadrant and a negative anomaly in the northeast quadrant (Figure 2a, bottom). Orientation of the dipole in CHL anomaly is a function of the rotational sense of the eddy as well as the propagation direction in relation to the ambient CHL field.

This process has been investigated in detail in the eastern subtropical South Pacific (Chelton et al. 2011a). Eddies in this region (Figure 1, "SEP") have a smaller mean amplitude than the global average for the same latitude band (mean SSH anomaly of $3.2 \mathrm{~cm}$ versus $6.2 \mathrm{~cm}$ ), although their radial scale is approximately the same $(110 \mathrm{~km})$. As such, these eddies tend to be less nonlinear than the global average, with $u / c>1$ for $87 \%$ of them. A complex relationship 
exists between SSH and CHL (Figure 2c), with eddy-driven perturbations most pronounced in the areas of strongest CHL gradients. A strong mean gradient in CHL is also present in this region, oriented meridionally in the western part and zonally in the eastern part in proximity to the coast. Removal of the large-scale gradients and mean seasonal cycle allows the eddy signals to emerge more clearly. Westward co-propagation of SSH and CHL is readily apparent, and individual eddy trajectories delineate the streaks in the anomaly fields (Figure 2d,e).

Compositing the data into eddy-centric coordinates, oriented relative to the large-scale mean gradient, yields dipole patterns characteristic of eddy stirring (Figure 2b). Although the dipole structures are qualitatively similar to the theoretical prediction (Figure 2a) there is a subtle difference: the magnitudes of the leading poles are higher in amplitude than the trailing poles. This asymmetry is apparently a result of the trailing edge of the eddy interacting with an ambient CHL field that has recently been under the influence of the leading edge of the eddy (Chelton et al. 2011a). Similar dipole patterns emerged from an eddy-centric analysis of eddy features in the Sargasso Sea (Siegel et al. 2011).

\subsection{Eddy Trapping}

Nonlinear eddies tend to trap the fluid contained in their interiors (Flierl 1981, Provenzale 1999). The composition of the trapped fluid depends on the process of eddy formation as well as the local gradients in physical, chemical, and biological properties. These properties can be maintained over long time periods, depending on ring evolution and exchange with the surrounding water masses. Gulf Stream Rings provide a classic example (Wiebe \& Joyce 1992) (Figure 3a). Cyclonic meanders pinch off cold-core rings that trap nutrient rich, high CHL slope water from the landward side of the Gulf Stream, whereas anticyclonic meanders pinch off warm-core rings that trap oligotrophic low CHL water from the Sargasso Sea. A contrasting example comes from the Leeuwin current (Figure 3b), which can spawn anticyclonic eddies with enhanced CHL derived from the coastal region (Moore et al. 2007). Trapped fluid is not unique to rings and boundary currents, and it is a common characteristic of nonlinear eddies in the open ocean (e.g., Menkes et al. 2002).

The trapping mechanism is evident in eddy-centric composites from the Gulf Stream region (Gaube et al. 2014). Cyclones from the region labeled "GS" in Figure 1 contain positive CHL anomalies in their interiors, and anticyclones contain negative CHL anomalies (Figure 4a,b). In both cases the anomalies appear as a monopole structure, in contrast to the dipole structure produced by eddy stirring (Figure 2b). More importantly, these CHL anomalies are present at the initial time of eddy detection (Figure 4c,d), suggesting they originated from the process of eddy formation. Note that the region over which this analysis was performed is large enough to include not only Gulf Stream rings, but also mid-ocean eddies; there is no distinction between them in the eddy-centric composites. In some regimes, such as the Agulhas retroflection, fluid trapped in rings can propagate well into the ocean interior, providing significant lateral fluxes of physical, chemical, and biological properties Lehahn et al. (2011).

\subsection{Eddy Pumping}

This mechanism can be conceptualized by considering a density surface with mean depth coincident with the base of the euphotic zone. This surface is perturbed vertically by the formation, evolution, and destruction of mesoscale features. Three types of features are schematized in Figure 5. Cyclones and anticyclones dome and depress the seasonal and main pycnoclines, respectively. Mode-water eddies are comprised of a lens-shaped disturbance that 
raises the seasonal pycnocline and lowers the main pycnocline. During eddy formation and intensification (Figure 5, top), shoaling density surfaces in cyclones and mode-water eddies lift nutrients into the euphotic zone, where they are rapidly utilized by the biota. Deepening of the isopycnals in anticyclones pushes nutrient-depleted water out of the well-illuminated surface layers. The asymmetric light field thus rectifies vertical displacements of both directions into a net upward transport of nutrients. Two aspects of this process favor complete utilization of the upwelled nutrients. First, the time scale for biological uptake is fast (order of days) with respect to the physical supply mechanism (eddy lifetimes on the order of months). Second, because the nutrient enhancement takes place in the eddy's interior, the circulation tends to isolate it from the surrounding waters, which allows biomass to accumulate until the nutrients are exhausted.

Evidence for the eddy pumping mechanism is also present in the eddy-centric anomalies from the Gulf Stream region (Figure 1, "GS"). To begin with, the positive CHL anomaly monopoles in cyclones and negative CHL anomaly monopoles in anticyclones (Figure 4, left) are consistent with expectations based on the conceptual model for eddy pumping - although monopole structures of these polarities are ambiguous with respect to eddy trapping and pumping (Gaube et al. 2014). As stated above, the presence of these anomalies at the time of first detection is consistent with trapping. However, the signature of eddy pumping is manifested by a subtle trend that barely exceeds the associated uncertainties: as cyclones intensify in the first twelve weeks of their lifetimes (Figure 4c), CHL anomalies also increase (Figure 4d). In contrast, the negative CHL anomaly in anticyclones is more stable over time during the same interval.

It is important to note that the eddy-centric analysis based on sea level cannot distinguish between mode-water eddies and regular anticyclones. Because steric height in mode-water eddies is dominated by downward displacement of the main pycnocline, they appear as positive anomalies in sea level, indistinguishable from regular anticyclones both in terms of SSH and their rotational velocities (McGillicuddy et al. 2007, Sweeney et al. 2003). As such, CHL anomalies generated by eddy stirring are expected to be the same in mode-water eddies as they are in regular anticyclones. In contrast, the expected response in terms of eddy pumping is confounding: positive for intensifying mode-water eddies and negative for intensifying regular anticyclones. As for trapping, the CHL signature would depend on the ambient gradients and whether the mechanism of formation was subduction from a remote source (Ebbesmeyer \& Lindstrom 1986) or local generation through eddy-wind interaction (McGillicuddy 2015).

The eddy-induced vertical flux depends not only on the structure of the isopycnal displacements, but also on the sense in which they are being perturbed by eddy dynamics. The latter characteristic is determined by the eddy's developmental stage, as well as eddy-eddy interactions during its lifetime. During the process of eddy decay (Figure 5, bottom), the sense of the vertical motions is opposite to that during formation/ intensification: relaxation of the density perturbations associated with eddy decay results in upper ocean downwelling in cyclonic features and mode-water eddies, while causing upwelling within anticyclones. An excellent example of the latter is provided by frictional spindown of warm core rings. A model by Franks et al. (1986) demonstrated how phytoplankton biomass enhancement could result from the nutrient input caused by the approximately $1 \mathrm{~m} \mathrm{day}^{-1}$ vertical velocities at ring center. Uptake rates of nitrate and silicic acid observed in the same ring which were sufficient to utilize the upward flux of nutrients (Nelson et al. 1989). 


\subsection{Eddy-wind interaction}

It was recognized long ago that the superposition of a wind-driven Ekman flow on a mesoscale velocity field gives rise to ageostrophic circulations involving significant vertical transports (Niiler 1969, Stern 1965). Submesoscale patches of vertical velocity result from the generalized Ekman divergence, which includes vortex stretching terms associated with advection of the interior vorticity by the boundary layer velocity. For a uniform wind stress applied to a radially symmetry eddy, this effect creates a dipole of upwelling and downwelling, the structure of which depends on the direction of the wind and the vorticity of the eddy (see Figure 4.33 of Flierl and McGillicuddy, 2002).

The presence of mesoscale variability in the ocean affects the wind stress itself, via two different processes. First, there is a feedback from sea surface temperature. Cooler ocean temperatures tend to stabilize the marine atmospheric boundary layer (MABL), decoupling it from winds aloft; conversely, warmer ocean temperatures tend to destabilize the MABL thereby decreasing vertical shear in the wind. The net effect is to increase surface wind speeds over warmer water and decrease them over colder water, leading to measurable differences in wind stress, its curl, and therefore Ekman pumping (Chelton et al. 2004). Second, there is a direct effect on the stress due to eddy-driven surface currents. That is, higher stress occurs on the flank of the eddy where the wind opposes the surface current, with lower stress on the flank of the eddy where the wind and the current are in the same direction (Figure 6a). The net result is Ekman suction (upwelling) in the interiors of anticyclones (Figure 6b) (Dewar \& Flierl 1987, Martin \& Richards 2001), and Ekman pumping (downwelling) in the interiors of cyclones (Gaube et al. 2013). In contrast to the prior two mechanisms of eddy-wind interaction, the vertical velocity field resulting from eddy-induced Ekman pumping is a monopole located at eddy center that does not depend on the direction of the wind.

Gaube et al. (2015) assessed the relative magnitudes of these three processes, finding that the sea surface temperature effect is generally smaller than the other two. Magnitudes of the vertical velocities induced by vorticity advection tend to be larger than those arising from eddyinduced Ekman pumping. However, the integrated impact depends critically on the structure of the associated vertical velocity fields. Specifically, the relative persistence of the monopole generated by the surface current stress effect overshadows the constantly-fluctuating dipole created by vorticity advection (see Gaube et al. (2015), Figures 8 and 9).

In nutrient limited conditions, eddy induced Ekman pumping is thus expected to produce positive CHL anomalies in anticyclones (upwelling), and negative CHL anomalies in cyclones (downwelling). This is precisely the pattern observed in eddy-centric composites of CHL anomaly and eddy induced Ekman pumping from the South Indian Ocean (Figure 4e,f). Timeseries of CHL anomaly (Figure 4g,h) reveal CHL anomalies are present at the time of eddy detection, suggesting the eddy trapping mechanism is also at work. Indeed, both satellite data and in situ process studies (Moore et al. 2007, Waite et al. 2007) have shown that highchlorophyll waters of coastal origin can be entrained into anticyclones of the Leeuwin Current (Figure 3b). However, the time series presented in Figure 4g,h also show that the positive CHL anomalies in anticyclones are significantly higher in weeks 6-11 as compared with weeks 1-4, which is consistent with eddy-induced Ekman pumping. Martin and Richards (2001) cited this process as a potential contributor to nutrient flux in an anticyclone in the northeast Atlantic. Eddy-induced Ekman pumping has also been invoked as an explanation for an extraordinary bloom of diatoms deep in the euphotic zone of a mode-water eddy in the Sargasso Sea 
(McGillicuddy et al. 2007) as well as near-surface CHL variations in the South China Sea (Li et al. 2014).

\subsection{Impacts on mixed layer depth}

The presence of geostrophic motions and their associated vorticity produces local variations in the effective Coriolis frequency, which can affect propagation characteristics of near-inertial waves (e.g., Kunze 1985). Regions of negative vorticity can focus and amplify of such waves, thereby augmenting shear, potentially leading to increased vertical mixing. Simulations by Klein and Hua (1988) illustrated the mesoscale heterogeneity in mixed layer depth that can arise from this process in a quasigeostrophic flow field forced by a uniform wind. This "inertial Ekman pumping" creates a broad spectrum of variations in mixed layer depth, although an eddy-scale signal is prominent.

Mixed layer depth is also modulated by the local changes in stratification driven by eddyinduced vertical isopycnal displacements. For example, in a cyclonic eddy, upward doming of the pycnocline increases stratification in the upper ocean, thereby shallowing the mixed layer depth for a given amount of turbulent kinetic energy from the surface. Conversely, downward deflection of the pycnocline by an anticyclonic eddy tends to reduce upper ocean stratification, thereby allowing the same amount of turbulent kinetic energy to create a deeper mixed layer. These direct impacts of the local stratification tend to be augmented by air-sea heat flux anomalies resulting from the associated perturbations in sea surface temperature (Williams 1988). For example, consider a situation in which the mean SST is such that there is no net sensible heat transfer to or from the atmosphere. Cold sea surface temperature anomalies in cyclones tend to draw heat into the ocean from the atmosphere, further increasing stratification in those features relative to the ambient waters. Similarly, warm sea surface temperature anomalies in anticyclones tend to release heat from the ocean into the atmosphere, cooling the surface ocean and thereby enhancing convection. The tendency for anticyclonic eddies to have deeper mixed layers than cyclones has been noted in the Gulf Stream (Dewar 1986), the northeast Atlantic (Williams 1988), the North Pacific (Kouketsu et al. 2012), and the South Indian Ocean (Dufois et al. 2014, Gaube et al. 2013). In fact, Dufois et al. (2014) have offered deeper mixed layers (Figure 7) as an alternative explanation for long-lived $\mathrm{CHL}$ anomalies in anticyclones of the South Indian Ocean (Figure 4e-h). Differentiating between enhanced mixing and eddyinduced Ekman pumping is difficult in this case, as both mechanisms tend to produce CHL anomalies of the same sign in this nutrient-limited regime. In a light-limited regime, eddy-driven variations in mixed layer depth would presumably produce the CHL anomalies of the opposite sign: shallower (deeper) mixed layers in cyclones (anticyclones) would lend themselves to higher (lower) CHL (Table 1).

\subsection{Mechanisms of CHL enhancement in the peripheries of anticyclonic eddies}

In contrast to the dipole and monopole anomalies of CHL described above, annular ringshaped patterns have been observed around the peripheries of eddies, particularly anticyclones. Although such patterns have yet to emerge in eddy-centric composites of many eddies, synoptic snapshots have revealed these features in a variety of regimes, including the Southern Ocean (Kahru et al. 2007) (Figure 8, top), the Gulf of Alaska (Mizobata et al. 2002), and the Mozambique channel (José et al. 2014). Qualitatively similar patterns have been produced in a variety of models (José et al. 2014, Lapeyre \& Klein 2006, Lévy \& Klein 2004, Lima et al. 2002, Mahadevan et al. 2008) (Figure 8, bottom). Two basic mechanisms have been invoked to 
explain these annular patterns: (1) lateral entrainment of streamers of high-CHL water from nearby coastal or frontal regions, and (2) local enhancement via either stratification in lightlimited systems or nutrient supply via upwelling along the eddy periphery. The latter can arise in submesoscale patches of upwelling and downwelling associated with meandering of the circular front that delineates the outer edge of an eddy (McGillicuddy et al. 1995). Upwelling rates in such features can be as high as 10-100 $\mathrm{m} \mathrm{d}^{-1}$ as a result of eddy-wind, eddy-eddy, and/or eddyfront interactions (Mahadevan et al. 2008, Martin \& Richards 2001, Yoshimori \& Kishi 1994).

These upwelling rates that occur at the submesoscale are much larger than those characteristic of the eddy-scale itself. However, these intense vertical motions are also associated with swift horizontal currents characteristic of frontal regions. As such, a water parcel transported into the euphotic zone by a submesoscale upwelling cell can be rapidly advected into a submesoscale downwelling cell where that same parcel can be transported back out of the euphotic zone. The degree to which the upwelled nutrients will be utilized by the biota depends on the relative time scales of the supply and uptake processes. This is of course a function of the dynamical regime and the local chemical and biological environment (see review by Williams and Follows (2003)). Another key factor is the degree of reversibility along the upwelling and downwelling trajectory. Both vertical mixing and lateral dispersion can lend a degree of irreversibility to the process, making the nutrient content of the downwelled water less than that which was upwelled, resulting in a net transport of nutrients (Martin \& Richards 2001, Martin et al. 2001).

\subsection{Global perspective}

The preceding sections (3.1-3.6) illustrate the variety of mechanisms by which eddies can shape CHL distributions in the upper ocean. A global perspective is facilitated by examination of the correlation between satellite measurements of SSH and CHL (Figure 9). Areas of positive correlation are indicative of positive CHL anomalies associated with anticyclonic eddies (positive SSH anomaly) and negative CHL anomalies with cyclonic eddies (negative SSH anomaly). Conversely, regions of negative correlation are indicative of positive CHL anomalies associated with cyclonic eddies, and negative CHL anomalies associated with anticyclones. The coherent regional structure in this correlation strongly suggests systematic variations in the mechanisms of mesoscale physical-biological interactions in the global ocean (Gaube et al. 2014).

A prime example of negative correlation occurs in the Gulf Stream region. Eddy-centric analysis (Figure 4a-d) suggests both trapping (Figure 3a) and eddy pumping (Figure 5) are at work. Negative correlation is observed in other western boundary current systems and their midlatitude extensions, including the Kuroshio Current, the Agulhas Current and BrazilMalvinas Confluence. Similarly, most eastern boundary current systems, such as the California Current, the Peru-Chile Current and the Benguela Current are characterized by negative correlation. Regions of negative correlation are also observed in the open ocean, such as northeast of Madagascar and to the east of the Hawaiian Islands in the North Pacific.

A prominent feature of positive correlation resides in the South Indian Ocean. Eddies in this region exhibit the signature of trapping, likely associated with high-CHL anticyclones and low-CHL cyclones spawned from the Leeuwin Current (Figure 3b; Figure 4h). High CHL in anticyclones and low CHL in cyclones may be maintained by (a) eddy induced Ekman pumping (Figure 4e,f) and/or (b) eddy impacts on mixed layer depth (Figure 7). These same mechanisms may be operating in other regions of positive correlation, such as the central South Pacific, 
subtropical North and South Atlantic and around the Hawaiian Islands in the central North

446 Pacific.

The SSH-CHL cross-correlation along the line in the southeast Pacific (Figure 9)

\section{EDDY IMPACTS ON MEAN PROPERTIES AND FLUXES}

Whereas the study of eddy-driven variability is guided by observations, quantification of their integrated impact on mean properties of the system and associated biogeochemical fluxes ultimately relies on models. A wide variety of approaches have been used to address this question, ranging from idealized process-oriented formulations to more realistic simulationoriented configurations. These approaches are complementary in a number of ways, not the least of which is that the former provide conceptual frameworks for diagnosis of more complex simulations. For example, Lee and Williams (2000) evaluated eddy-driven fluxes in a periodic channel forced with wind stresses and heat fluxes that mimic subtropical to subpolar environments. Adopting the Gent et al. (1995) formalism, they derive eddy-induced advection and diffusion from the time-averaged and zonally-averaged tracer equations. Their results show that eddy-induced advection and diffusion of nutrients oppose each other in the upper ocean, whereas they reinforce each other in the deep ocean (Figure 10a). Wind-driven flows also play an important role in the near-surface layer (Figure 10b): lateral Ekman fluxes into the 
subtropical gyre oppose the outward eddy-induced advection, and downwelling of nutrients driven by Ekman convergence counters upward eddy-induced advection (eddy pumping). Idealized models have also elegantly demonstrated that resolving mesoscale eddies may not be adequate for assessing the mean fluxes. Lévy et al. (2001) simulated frontal instability at resolutions of 10,6 , and $2 \mathrm{~km}$, finding that new production systematically increased with resolution. Productivity of the $2 \mathrm{~km}$ model was almost a factor of three higher than the $10 \mathrm{~km}$ model, clearly demonstrating the importance of submesoscale processes.

It is only relatively recently that truly eddy-resolving models have been run on basin to global scales (Hecht \& Hasumi 2008), and computational limitations generally preclude simulations much longer than 5-10 years for coupled physical-biological-biogeochemical applications. Such integrations are typically long enough to provide several years of quasiequilibrium solution for analysis subsequent to the transients associated with adjustment to initial conditions. However, these solutions can be far from true equilibrium, as illustrated in a recent study by Lévy et al. (2012b) comparing the results of $1 / 54^{\circ}$ and $1 / 9^{\circ}$ resolution models integrated for 50 years in an idealized double-gyre simulation reminiscent of the North Atlantic (Figure 11). After 50 years, the two models show systematic regional differences in total production of $\pm 60 \%$. A particularly salient feature of the higher resolution model is a $\sim 30 \%$ decrease in productivity of the subtropical gyre, attributed to a long-term deepening of the nitracline in that region. In other words, mesoscale and submesoscale dynamics produce not only local fluctuations, but also changes in the mean state of the system. This caveat must be kept in mind when interpreting the results from shorter-term integrations described below.

\subsection{Subtropical Gyre}

The role of eddies in supplying nutrients in the subtropical gyre has been debated for some time. Comparison of two hydrographic profiles sampled one month apart off Bermuda documented an apparently eddy-driven nutrient injection event that could account for $20-30 \%$ of the annual new production (Jenkins 1988b). High-resolution transects in the Pacific (Venrick 1990) and Atlantic (Strass 1992) revealed mesoscale variations in chlorophyll consistent with eddy-induced upwelling. Surveys of a cyclone in the lee of Hawaii documented increased primary production in its interior, and extrapolation of that result suggested a $20 \%$ enhancement of global primary production by mid-ocean eddies (Falkowski et al. 1991). A variety of models have been brought to bear on this question, but the magnitude of the eddy-induced flux and its utilization is model-dependent (Eden \& Dietze 2009, Martin \& Pondaven 2003, McGillicuddy et al. 2003, McGillicuddy et al. 1998, McGillicuddy \& Robinson 1997, Oschlies 2002, Oschlies \& Garcon 1998, Pasquero et al. 2005).

An example is provided in Figure 12, in which the horizontal and vertical nutrient fluxes in a one-tracer light-limited nutrient transport model have been decomposed into their time-mean and eddy-driven components. Although this decomposition is different from that used by Lee and Williams (2000) to distill Figure 10, some commonalities are evident in the results. In the subtropical gyre, mean vertical advection constitutes a sink of nitrate, owing to the downwelling caused by Ekman convergence. Eddy-induced vertical advection is a source of nitrate, which is sufficient to overcome the mean downward transport such that the total vertical advection is a net source of nitrate. Note that Lee and Williams (2000) predicted the opposite, with Ekman downwelling overshadowing eddy pumping (Figure 10b). In other aspects, the realistic simulation is more similar to the idealized model. Horizontal advection (Figure 12) is near zero over much of the subtropical gyre due to the low concentration of nitrate in the surface waters of 
this region. However, horizontal advection is a net source of nutrients along the northern edge of the gyre. This lateral flux of nitrate into the gyre arises mostly from the mean fields, roughly consistent with the Ekman flux of nitrate described by Williams and Follows (1998).

\subsection{Subpolar Gyre}

New production in the subpolar gyre is considerably higher than that in the subtropical gyre (Figure 12), due to a combination of vigorous vertical mixing and mean upwelling from divergence of the wind-forced Ekman surface current. Interestingly, the time-varying component of vertical advection is negative over a large portion of this region, especially in areas where the wintertime mixed layer depth is deepest. In the southern part of the gyre, the magnitude of this sink is sufficient to overcome the mean upward vertical advection, causing the total vertical advection to be negative in that area. Horizontal advection is also important in this region. The large area of negative net lateral flux arises primarily from mean horizontal advection. Eddy-driven horizontal advection in this area varies on smaller scales but generally tends to reinforce the mean. This negative lateral flux is due to northeastward flow of the North Atlantic importing lower concentrations of nitrate into the subpolar gyre.

In contrast to the subtropical gyre where eddy-driven fluxes constitute a net source of nutrients, it appears that the oceanic mesoscale has a significant impact on nutrient removal from the euphotic zone in the subpolar gyre. A similar feature is evident in the simulations of Oschlies (2002), suggesting this result is not model dependent. Diagnosis of the solutions shown in Figure 12 suggests that the downward nutrient flux results from mesoscale processes associated with restratification following deep convection (Figure 13). Indeed, mesoscale and submesoscale dynamics have been shown to play a key role in the process of restratification (Mahadevan et al. 2012, Marshall 1997, Nurser \& Zhang 2000). Lévy et al. (1998, 1999) described how mesoscale restratification increases productivity following convection by releasing phytoplankton from light limitation. The eddy-induced nutrient sink shown in Figure 13 is the counterpart to that process deeper in the water column: the same mesoscale dynamics that restratify the near-surface region pump nutrients out of the euphotic zone. This removal takes place at a time when the ambient nutrients are in excess of limiting concentrations, so there is no immediate reduction of productivity. However, this process would tend to decrease productivity on seasonal to annual time scales, insofar as a portion of the nutrients brought into the euphotic zone by wintertime mixing are pumped back downward prior to utilization. On the other hand, Mahadevan et al. (2012) have suggested that the mixed layer eddies involved in restratification could increase overall productivity.

\subsection{Coastal upwelling systems}

Upwelling regions along coastal margins support some of the most productive marine ecosystems on earth. These systems also tend to have high eddy kinetic energy, owing to the squirts, jets, filaments, and eddies that are formed when along-shore wind stress generates an Ekman divergence at the coast that leads to upwelling. In contrast to the oligotrophic waters of the open ocean where eddy-induced nutrient fluxes can increase productivity, it appears that eddy-driven processes decrease productivity in eastern boundary upwelling systems (Gruber et al. 2011). Two mechanisms appear to be at work: lateral stirring and subduction.

First, stirring by mesoscale structures transports upwelling-derived biomass offshore, thereby reducing biomass in the upwelling zone itself. This process was noted by Rossi et al. (2008) in their analysis of Finite Size Lyapunov Exponents (FSLEs) and chlorophyll 
distributions in the Benguela and Canary upwelling systems. FSLEs provide a measure of lateral stirring, and can be computed directly from satellite altimeter data. Rossi et al. found that chlorophyll concentration was inversely correlated with FSLEs in these systems, such that the more vigorous stirring in the Benguela system was associated with lower chlorophyll concentrations than the Canary system. The role of mesoscale processes in reducing phytoplankton biomass was quantified in a model of the Benguela system, indicating eddydriven transports are responsible for $30-50 \%$ of the offshore fluxes of biological tracers (Hernández-Carrasco et al. 2014).

The second mechanism involves offshore subduction of upwelled nutrients. Gruber et al. (2011) diagnosed the eddy-induced nitrogen fluxes from a high-resolution coupled-physical biological model of the California Current system (Figure 14). As expected, vertical eddyinduced fluxes are positive close to the coast, where mesoscale dynamics are intimately involved in the upwelling process. Lateral eddy fluxes transport nitrogen away from the coast in the surface layer, in concert with downward eddy-induced transport offshore - the net result of which is subduction into the ocean interior. These subducted nutrients occupy an intermediate layer that is distinct from that which feeds the Ekman-driven upwelling cell, thus constituting a "leak" of nutrients that decreases the overall productivity of the system.

In addition to eddy-induced transports, there are special biogeochemical transformations that take place within eddies in upwelling systems. For example, hotspots for fixed-nitrogen loss have been observed in association with anticyclonic eddies in the Peru oxygen minimum zone (Altabet et al. 2012, Bourbonnais et al. submitted, Stramma et al. 2013). However, observations of this process are currently so sparse that quantification of their integrated impact on nutrient budgets is not yet possible.

\subsection{Other regional Studies}

Growing awareness of the diversity of eddy impacts on biological systems has led to increasing numbers of regional studies. For example, analysis of satellite-based observations of sea level and ocean color in the Weddell-Scotia confluence in the Southern Ocean indicates that cyclonic eddies enhance biological production (Kahru et al. 2007). Both observations and models suggest anticyclonic eddies enhance production in the northern Gulf of Alaska, by virtue of the iron they transport from the coastal margin into the interior (Crawford et al. 2007, Xiu et al. 2011). A high-resolution model of the South China Sea suggests cyclonic eddies are an important source of nutrients to the surface ocean in that region, triggering shifts in phytoplankton species composition toward diatoms, thereby increasing export flux and associated cycling of carbon (Xiu \& Chai 2011). On the other hand, observations in the South China Sea have revealed enhanced export fluxes in anticyclones, attributed to submesoscale upwelling along eddy peripheries (Zhou et al. 2013; Cf. section 3.6). Using data from shipboard surveys, Prasanna Kumar (2007) estimated that eddy pumping increases productivity in the Bay of Bengal by a 50-100\%. In a model of the Arabian Sea, Resplandy et al. (2011) found that multiple mesoscale processes contributed to regional nutrient budgets, namely (1) lateral advection from coastal upwelling zones into the interior via jets and filaments, (2) eddy pumping, and (3) eddy-driven restratification following monsoonally-driven convective mixing. Such integrative analyses seeking to assess the net impact of eddies on various systems draw heavily on the growing data base provided by in situ process studies (Supplementary Table). 


\section{EDDY-DRIVEN BIOLOGICAL REYNOLDS STRESSES}

Three-dimensional coupled physical-biological models are typically formulated in terms of the mean field approximation, in which properties $\varphi_{i}$ in a given grid cell are assumed to be adequately represented by their mean value $\bar{\varphi}_{l}$. Of course, fluctuations $\varphi_{i}^{\prime}$ exist; the Reynolds decomposition expresses the full field as a sum of mean and fluctuating components, the latter of which average to zero: $\varphi_{i}=\bar{\varphi}_{l}+\varphi_{i}^{\prime}$. Biological and biogeochemical transformations typically involve nonlinear functions, so even though $\overline{\varphi_{l}^{\prime}}=0$, the average value of such a function operating on the fluctuations $\overline{f\left(\varphi_{l}^{\prime}\right)}$ does not necessarily vanish. Moreover, the average product of two constituents $\overline{\varphi_{l} \varphi_{j}}$ includes contributions not only from the means $\overline{\varphi_{i}} \overline{\varphi_{j}}$ but also from the "biological Reynolds stresses" $\overline{\varphi_{l}^{\prime} \varphi_{J}^{\prime}}$. These effects have been examined in a variety of idealized frameworks, including theoretical (Goodman 2011, Goodman \& Robinson 2008), onedimensional (Brentnall et al. 2003), and two-dimensional (Wallhead et al. 2008), providing quantification of the limitations of the mean field approximation in such systems.

It is only recently that the net impact of fluctuations in biological properties has been examined in three-dimensional simulations of mesoscale and submesoscale turbulence (e.g., Wallhead et al. 2013). Lévy and Martin (2013) diagnosed these terms from their $1 / 54^{\circ}$ resolution physical-biological model of the North Atlantic, making the distinction between "eddy reactions" and "eddy transports" of the type described in earlier sections. Their findings illustrate the eddy reaction terms play qualitatively different roles for different state variables (see Lévy and Martin's Figure 9). For nitrate, the eddy reactions are generally small relative to the mean biogeochemical reactions, with the latter being balanced by a complex latitudinally-dependent combination of vertical mixing, mean advection, and eddy transport. In contrast, eddy reactions are amongst the largest terms in the phytoplankton equation, negative in sign and varying inversely with the mean reaction term. In other words, nonlinear interactions at the mesoscale and submesoscale reduce primary productivity. For zooplankton, the eddy reactions vary with latitude: they are small south of $28^{\circ} \mathrm{N}$, increase secondary productivity between $28^{\circ} \mathrm{N}$ and $40^{\circ} \mathrm{N}$, and decrease secondary productivity north of $40^{\circ} \mathrm{N}$. Although the details of these diagnoses may be model dependent, these findings clearly illustrate that eddy-driven fluctuations can be rectified by nonlinear biogeochemical transformations - and that the magnitudes of the eddy reactions are on the order of 5-15\% of the means (see Lévy and Martin's Figure 7). Whereas complete knowledge of a modeled system lends itself to relatively straightforward computation of biological Reynolds stresses, observational assessment is made more challenging by the lack of multiscale resolution of all relevant quantities. Initial attempts to quantify eddy-driven biological Reynolds stresses suggest more modest magnitudes than those derived from models (Martin et al. submitted).

\section{INFLUENCES ON PHYTOPLANKTON COMMUNITY COMPOSITION AND DIVERSITY}

Eddy-induced disturbances in the physical and chemical environment can bring about changes in the communities of primary producers. In fact, such biological responses may regulate the net impact on biogeochemical fluxes described above. For example, Goldman (1988) suggested the "spinning wheel" concept in which the background state of oligotrophic systems is dominated by small phytoplankton growing primarily on nutrients that are recycled through the microbial loop. This state is episodically perturbed by the input of nutrients to the base of the euphotic zone, causing a shift in phytoplankton species composition from picoplankton toward much larger cells such as diatoms. In such a scenario, these large cells 
would sink rapidly once the nutrient enhancement was depleted, thereby contributing a disproportionately large fraction of new versus total primary production. Laboratory culture experiments have confirmed that diatoms can grow rapidly enough to produce significant blooms even at the low light levels characteristic of the base of the euphotic zone (Goldman \& McGillicuddy 2003). Indeed, evidence for mesoscale variations in diatom abundance has been observed in a variety of oceanographic environments, including the North Pacific (Brzezinski et al. 1998), Hawaiian lee eddies (Olaizola et al. 1993, Seki et al. 2001, Vaillancourt et al. 2003), the Hawaiian Ocean Time-series (Letelier et al. 2000), the Sargasso Sea (Krause et al. 2010, McGillicuddy et al. 2007), and the Bermuda Atlantic Time-series (Krause et al. 2009, McNeil et al. 1999, Sweeney et al. 2003). Bibby and Moore (2011) found that the response of diatom populations to eddy-induced upwelling in the subtropical Atlantic and Pacific depends on the nitrate to silicate ratio of the upwelled water. In several cases, mesoscale diatom blooms have been linked directly to enhanced export (Allen et al. 2005, Benitez-Nelson et al. 2007, Bidigare et al. 2003).

Even more general relationships between the mesoscale environment and plankton community structure have emerged from both observations and models. For example, Rodriguez et al. (2001) identified a linear relationship between the size-abundance spectrum (SAS) of phytoplankton and vertical velocity in the northwestern Alboran Sea. Specifically, upwelling (downwelling) motions tended to increase (decrease) the relative abundance of large phytoplankton, thereby flattening (steepening) the SAS - suggesting that mesoscale motions exert a primary control on size structure of phytoplankton communities.

Models have been used to address a growing interest in the influence of mesoscale dynamics on the diversity of open ocean phytoplankton populations, challenging the assumption of environmental homogeneity in Hutchinson's (1961) classic "paradox of the plankton." Using a two-species model with a uniform distribution of limiting resource embedded in quasigeostrophic turbulence, Bracco et al. (2000) show how coherent vortices can preserve diversity by isolating populations from the surrounding fluid: a less-fit species can persist in conditions in which they would otherwise be outcompeted if the more-fit species were not excluded by the lack of mixing. Perruche et al. (2011) considered a case in which the mesoscale motions influenced the distribution of resources (nutrients), finding that surface quasigeostrophic turbulence facilitated coexistence of two competing phytoplankton species. Upwelling in filaments stimulated both species, whereas eddy cores serve as refugia as found by Bracco et al. (2000).

Additional studies of phytoplankton diversity have been facilitated by the development of the so-called "Darwin" model in which many tens of species ("ecotypes") are stochastically assigned physiological characteristics with basic allometric tradeoffs (Follows et al. 2007). By allowing the suite of ecotypes to compete in a three-dimensional model ocean, phytoplankton species composition is an emergent property of the system. Clayton et al. (2013) examined an eddy-permitting case, finding that regions of high eddy kinetic energy in western boundary currents coincide with high diversity in the simulated phytoplankton community (Figure 15a). These "hotspots" in diversity are supported by the confluence of multiple upstream populations, local stimulation via nutrient supply, and environmental variability provided by eddies. Lévy et al. (2014) quantified the impact of dispersal on diversity by applying the Darwin biological module into eddy-resolving simulations in an idealized North Atlantic domain (depicted in Figure 11a). Their counterintuitive results (Figure 15b) suggest that increasing dispersion leads to increasing local diversity (order 10-100 km scales) and decreasing regional diversity (order 
$1000 \mathrm{~km}$ scales). In other words, hydrodynamic transport leads to the dominance of fewer species overall, but those fewer species occur over larger ranges with a higher degree of coexistence. Studies of this type are still quite novel, and the data needed to test such models is only beginning to emerge (Clayton et al. 2014, Follows et al. 2007).

\section{EFFECTS ON HIGHER TROPHIC LEVELS}

Eddy dynamics can perturb oceanic ecosystems, influencing trophic levels ranging from primary producers (as described in section 6) to top predators. For example, Wiebe and Flierl (1983) described changes in zooplankton (euphausiid) species distributions during the decay of a cold core ring: native cold water species such as Nematoscelis megalops emigrated, whereas warm water species such as Stylocheiron carinatum immigrated. These changes in distributional patterns were facilitated by vertical positioning behavior in the presence of a hydrodynamic environment that varies with depth. Specifically, descent of the N. megalops population during ring decay resulted in its exit from the region of trapped fluid, thereby bringing about expatriation. In contrast, the near-surface keeping behavior of $S$. carinatum subjects it to enhanced horizontal mixing within the mixed layer, thereby facilitating its invasion into the ring interior. Active vertical positioning also supports a mechanism for concentrating organisms within a mesoscale flow field: depth-keeping behavior in the presence of convergence (Genin et al. 2005, Olson \& Backus 1985).

Mesoscale phenomena are also relevant to the transport and survival of planktonic larvae. Lobel and Robinson (1986) noted a cyclonic eddy near Hawaii retained larval reef fishes for a time period sufficient to complete their pelagic developmental phase and resettle their native reefs. On the other hand, eddies also provide means for enhanced larval dispersion and population connectivity, both in the coastal margin (Mitarai et al. 2009) and in the deep sea (Adams et al. 2011). Bakun (2006) presented a conceptual framework in which eddy-driven variations in productivity offer competing tradeoffs in terms of larval survival: enhanced productivity improves early life nutrition at the expense of increased predator abundance, whereas suppressed productivity decreases the abundance of predators at the expense of poorer larval nutrition. These concepts have been invoked to explain mesoscale variations in the distribution of larval bluefin tuna (Alemany et al. 2010, Lindo-Atichati et al. 2012), sailfish, marlin, swordfish, and other species (Richardson et al. 2010).

Distributions of adult fishes have also been associated with the mesoscale environment. Based on catch data, cyclonic eddies appear to be home to higher abundances of bluefin tuna in the Gulf of Mexico (Teo \& Block 2010) and blue marlin in the vicinity of Hawaii (Seki et al. 2002). Based on acoustic and trawl surveys, mid-water fishes are associated with anticyclonic eddies in the Iceland Basin (Godø et al. 2012). Visual sightings of cetaceans (whales and dolphins) in the northern Gulf of Mexico indicated congregations in or near cyclones and in the confluence of cyclone-anticyclone pairs where zooplankton and micronekton prey abundances were higher (Davis et al. 2002). Seabirds of various kinds have been associated with the peripheries of eddies and convergence zones between them, including great frigate birds in the Mozambique channel (Tew Kai \& Marsac 2010, Weimerskirch et al. 2004), and albatross, terns, and shearwaters in the Southern Indian Ocean (Hyrenbach et al. 2006, Nel et al. 2001). The advent of electronic tagging and telemetry has facilitated investigation of mesoscale niche utilization and behavior by a diverse range of marine animals, including turtles (Gaspar et al. 2006, Kobayashi et al. 2011, Polovina et al. 2004), elephant seals (Bailleul et al. 2010, Campagna et al. 2006), shearwaters (Yoda et al. 2014), and penguins (Cotté et al. 2007). In 
many cases, association of these animals with mesoscale features is directly linked with foraging 767 behavior.

\section{CONCLUDING REMARKS}

Advances in theory, observation, and modeling have facilitated substantial progress in understanding of physical-biological-biogeochemical interactions in the ocean. It has become abundantly clear that the impacts of eddies varies regionally (section 3.7) by virtue of the wealth of processes that contribute (sections 3.1-3.7) and variations in the relative amplitudes at which those mechanisms are expressed. The longstanding debate about the magnitude of the eddyinduced nutrient source in the subtropics continues (section 4.1), whereas potential eddy-driven nutrient sinks have become apparent in subpolar gyres (section 4.2) and in coastal upwelling regions (section 4.3). Appreciation is growing for the role of mesoscale processes in biological dynamics, including eddy-induced Reynolds stresses (section 5), planktonic biodiversity (section 6), and niche utilization by higher trophic levels (section 7). Future prospects are bright for further progress in these areas as observational capabilities improve in towed instrumentation (Davis et al. 2005), autonomous platforms (Johnson et al. 2009), genomic methods to characterize planktonic communities (DeLong et al. 2006), and electronic tagging technologies (Block et al. 2001). Increased spatial resolution in upcoming altimeter missions (Fu \& Ubelmann 2013) and finer spectral resolution in ocean color missions (Del Castillo 2012) will enhance the abilities to characterize physical and biological properties in the upper ocean. Likewise, computational infrastructure and modeling capabilities continue to progress (Hecht \& Hasumi 2008). This confluence of advances in in situ observation, remote sensing, and modeling have set the stage to further elucidate the linkages between mesoscale and submesoscale dynamics (Lévy et al. 2012a), which is perhaps one of the most challenging and exciting prospects for future research in this area.

\section{Acknowledgments}

I gratefully acknowledge support from the National Science Foundation, the National Aeronautics and Space Administration, and the Holger W. Jannasch and Columbus O'Donnell Iselin Shared Chairs for Excellence in Oceanography. 


\section{References}

Abraham ER. 1998. The generation of plankton patchiness by turbulent stirring. Nature 391: $577-80$

Adams DK, McGillicuddy DJ, Zamudio L, Thurnherr AM, Liang X, et al. 2011. SurfaceGenerated Mesoscale Eddies Transport Deep-Sea Products from Hydrothermal Vents. Science 332: 580-83

Alemany F, Quintanilla L, Velez-Belchí P, García A, Cortés D, et al. 2010. Characterization of the spawning habitat of Atlantic bluefin tuna and related species in the Balearic Sea (western Mediterranean). Progress In Oceanography 86: 21-38

Allen JT, Brown L, Sanders R, Moore CM, Mustard A, et al. 2005. Diatom carbon export enhanced by silicate upwelling in the northeast Atlantic. Nature 437: 728-32

Altabet MA, Ryabenko E, Stramma L, Wallace DWR, Frank M, et al. 2012. An eddy-stimulated hotspot for fixed nitrogen-loss from the Peru oxygen minimum zone. Biogeosciences 9: 4897-908

Angel MV, Fasham MJR. 1983. Eddies and Biological Processes. In Eddies in Marine Science, ed. AR Robinson, pp. 492-524: Springer-Verlag

Bailleul F, Cotté C, C G. 2010. Mesoscale eddies as foraging area of a deep-diving predator, the southern elephant seal. Marine Ecology Progress Series 408: 251-64

Bakun A. 2006. Fronts and eddies as key structures in the habitat of marine fish larvae: opportunity, adaptive response and competitive advantage. Scientia Marina 70S2: 105-22

Benitez-Nelson CR, Bidigare RR, Dickey TD, Landry MR, Leonard CL, et al. 2007. Mesoscale eddies drive increased silica export in the subtropical Pacific Ocean. Science 316: 101721

Benitez-Nelson CR, McGillicuddy DJ. 2008. Mesoscale physical-biological-biogeochemical linkages in the open ocean: An introduction to the results of the E-FLUX and EDDIES programs. Deep Sea Res. II 55: 1133-38

Bibby TS, Moore CM. 2011. Silicate:nitrate ratios of upwelled waters control the phytoplankton community sustained by mesoscale eddies in sub-tropical North Atlantic and Pacific. Biogeosciences 8: 657-66

Bidigare RR, Benitez-Nelson C, Leonard CL, Quay PD, Parsons ML, et al. 2003. Influence of a cyclonic eddy on microheterotroph biomass and carbon export in the lee of Hawaii. Geophysical Research Letters 30: 1318

Block BA, Dewar H, Blackwell SB, Williams TD, Prince ED, et al. 2001. Migratory Movements, Depth Preferences, and Thermal Biology of Atlantic Bluefin Tuna. Science 293: $1310-14$

Bourbonnais A, Altabet MA, Charoenpong CN, Larkum J, Hu H, et al. submitted. N-loss isotope effects in the Peru oxygen minimum zone studied using a mesoscale eddy as a natural tracer experiment. Global Biogeochemical Cycles

Bracco A, Provenzale A, Scheuring I. 2000. Mesoscale vortices and the paradox of the plankton. Proceedings of the Royal Society of London B 267: 1795-800

Brentnall SJ, Richards KJ, Brindley J, Murphy E. 2003. Plankton patchiness and its effect on larger-scale productivity. Journal of Plankton Research 25: 121-40

Broecker WS, Peng TH. 1982. Tracers in the Sea. Palisades, New York: Lamont-Doherty Geological Observatory 
Brzezinski MA, Villareal TA, Lipschultz F. 1998. Silica production and the contribution of diatoms to new and primary production on the central North Pacific. Marine Ecology Progress Series 167: 89-104

Campagna C, Piola AR, Rosa Marin M, Lewis M, Fernández T. 2006. Southern elephant seal trajectories, fronts and eddies in the Brazil/Malvinas Confluence. Deep Sea Research I 53: $1907-24$

Charria G, F. Mélin, I. Dadou, M.-H. Radenac, and V. Garçon. 2003. Rossby wave and ocean color: The cells uplifting hypothesis in the South Atlantic Subtropical Convergence Zone. Geophys. Res. Lett. 30: 1125-1-4

Chelton DB, Gaube P, Schlax MG, Early JJ, Samelson RM. 2011a. The Influence of Nonlinear Mesoscale Eddies on Near-Surface Oceanic Chlorophyll. Science 334: 328-32

Chelton DB, Schlax MG. 1996. Global Observations of Oceanic Rossby Waves. Science 272: 234-38

Chelton DB, Schlax MG, Freilich MH, Milliff RF. 2004. Satellite Measurements Reveal Persistent Small-Scale Features in Ocean Winds. Science 303: 978-83

Chelton DB, Schlax MG, Samelson RM. 2011b. Global observations of nonlinear mesoscale eddies. Progress In Oceanography 91: 167-216

Chelton DB, Schlax MG, Samelson RM, de Szoeke RA. 2007. Global observations of large oceanic eddies. Geophys. Res. Lett. 34: L15606

Cipollini P, Cromwell D, Challenor PG, Raffaglio S. 2001. Rossby Waves Detected in Global Ocean Colour Data. Geophys. Res. Lett. 28: 323-26

Clayton S, Dutkiewicz S, Jahn O, Follows MJ. 2013. Dispersal, eddies, and the diversity of marine phytoplankton. Limnology and Oceanography: Fluids and Environments 3: 18297

Clayton S, Nagai T, Follows MJ. 2014. Fine scale phytoplankton community structure across the Kuroshio Front. Journal of Plankton Research 36: 1017-30

Cotté C, Park Y-H, Guinet C, Bost C-A. 2007. Movements of foraging king penguins through marine mesoscale eddies. Proceedings of the Royal Society of London B 274: 2385-91

Crawford WR, Brickley PJ, Thomas AC. 2007. Mesoscale eddies dominate surface phytoplankton in northern Gulf of Alaska. Progress In Oceanography 75: 287-303

d'Ovidio F, De Monte S, Alvain S, Danonneau Y, Lévy M. 2010. Fluid dynamical niches of phytoplankton types. Proceedings of the National Academy of Sciences 107: 18366-70

Dandonneau Y, Vega A, Loisel H, Penhoat Yd, Menkes C. 2003. Oceanic Rossby Waves Acting as a "Hay Rake" for Ecosystem Floating By-Products. Science 302: 1548-51

Davis CS, Thwaites FT, Gallager SM, Hu Q. 2005. A Three-axis Fast-tow Digital Video Plankton Recorder for Rapid Surveys of Plankton Taxa and Hydrography. Limnology and Oceanography: Methods 3: 59-74

Davis RW, Ortega-Ortiz JG, Ribic CA, Evans WE, Biggs DC, et al. 2002. Cetacean habitat in the northern oceanic Gulf of Mexico. Deep Sea Research I 49: 121-42

Del Castillo C. 2012. Pre-Aerosol, Clouds, and ocean Ecosystem (PACE) Mission Science Definition Team Report, NASA

DeLong EF, Preston CM, Mincer T, Rich V, Hallam SJ, et al. 2006. Community Genomics Among Stratified Microbial Assemblages in the Ocean's Interior. Science 311: 496-503

Dewar WK. 1986. Mixed layers in Gulf Stream rings. Dyn. Atmos. Oceans 10: 1-29

Dewar WK, Flierl GR. 1987. Some effects of wind on rings. Journal of Physical Oceanography 17: $1653-67$ 
Dufois F, Hardman-Mountford NJ, Greenwood J, Richardson AJ, Feng M, et al. 2014. Impact of eddies on surface chlorophyll in the South Indian Ocean. Journal of Geophysical Research: Oceans 119: 8061-77

Ebbesmeyer CC, Lindstrom EJ. 1986. Structure and origin of $18 \mathrm{C}$ water observed during the POLYMODE Local Dynamics Experiment. Journal of Physical Oceanography 16: 44353

Eden C, Dietze H. 2009. Effects of mesoscale eddy/wind interactions on biological new production and eddy kinetic energy. Journal of Geophysical Research 114: C05023

Falkowski PG, Ziemann D, Kolber Z, Bienfang PK. 1991. Role of eddy pumping in enhancing primary production in the ocean. Nature $352: 55-58$

Flierl GR. 1981. Particle motions in large-amplitude wave fields. Geophysical \& Astrophysical Fluid Dynamics 18: 39-74

Flierl GR, McGillicuddy DJ. 2002. Mesoscale and submesoscale physical-biological interactions. In The Sea, ed. AR Robinson, JJ McCarthy, BJ Rothschild, pp. 113-85. New York: John Wiley and Sons, Inc.

Follows MJ, Dutkiewicz S, Grant S, Chisholm SW. 2007. Emergent biogeography of microbial communities in a model ocean. Science 315: 1843-46

Franks PJS, Wroblewski JS, Flierl GR. 1986. Prediction of phytoplankton growth in response to the frictional decay of a warm-core ring. J. Geophys. Res. 91: 7603-10

Fu L-L, Ubelmann C. 2013. On the Transition from Profile Altimeter to Swath Altimeter for Observing Global Ocean Surface Topography. Journal of Atmospheric and Oceanic Technology 31: 560-68

Gaspar P, Georges J-Y, Fossette S, Lenoble A, Ferraroli S, Le Maho Y. 2006. Marine animal behaviour: neglecting ocean currents can lead us up the wrong track. Proceedings of the Royal Society of London B 273: 2697-702

Gaube P, Chelton DB, Samelson RM, Schlax MG, O'Neill LW. 2015. Satellite Observations of Mesoscale Eddy-Induced Ekman Pumping. Journal of Physical Oceanography 45: 10432

Gaube P, Chelton DB, Strutton PG, Behrenfeld MJ. 2013. Satellite observations of chlorophyll, phytoplankton biomass and Ekman pumping in nonlinear mesoscale eddies. Journal of Geophysical Research 118: 6349-70

Gaube P, McGillicuddy DJ, Chelton DB, Behrenfeld MJ, Strutton PG. 2014. Regional variations in the influence of mesoscale eddies on near-surface chlorophyll. Journal of Geophysical Research: Oceans 119: 8195-220

Genin A, Jaffe JS, Reef R, Richter C, Franks PJS. 2005. Swimming Against the Flow: A Mechanism of Zooplankton Aggregation. Science 308: 860-62

Gent PR, Willebrand J, McDougall TJ, McWilliams JC. 1995. Parameterizing Eddy-Induced Tracer Transports in Ocean Circulation Models. Journal of Physical Oceanography 25: 463-74

Godø OR, Samuelsen A, Macaulay GJ, Patel R, Hjøllo SS, et al. 2012. Mesoscale Eddies Are Oases for Higher Trophic Marine Life. PLoS ONE 7: e30161

Goldman JC. 1988. Spatial and temporal discontinuities of biological processes in pelagic surface waters. In Toward a Theory on Biological-Physical Interactions in the World Ocean, ed. BJ Rothschild, pp. 273-96. Dordrecht: D. Reidel

Goldman JC, McGillicuddy DJ. 2003. Impact of large marine diatoms growing at low light on episodic new production. Limnol. Oceanogr. 48: 1176-82 
936

937

938

939

940

941

942

943

944

945

946

947

948

949

950

951

952

953

954

955

956

957

958

959

960

961

962

963

964

965

966

967

968

969

970

971

972

973

974

975

976

977

978

979

980

Goodman L. 2011. Application of the Robinson biodynamical theory to turbulence. Dynamics of Atmospheres and Oceans 52: 8-19

Goodman L, Robinson AR. 2008. On the theory of advective effects on biological dynamics in the sea. III. The role of turbulence in biological-physical interactions. Proceedings of the Royal Society of London A 464: 555-72

Gower JFR, Denman KL, Holyer RJ. 1980. Phytoplankton patchiness indicates the fluctuation spectrum of mesoscale oceanic structure. Nature 288: 157-59

Gruber N, Lachkar Z, Frenzel H, Marchesiello P, Munnich M, et al. 2011. Eddy-induced reduction of biological production in eastern boundary upwelling systems. Nature Geosci 4: 787-92

Hecht MW, Hasumi H, eds. 2008. Ocean Modeling in an Eddying Regime, Vols. 177. Washington D.C.: American Geophysical Union. 409 pp.

Hernández-Carrasco I, Rossi V, Hernández-García E, Garçon V, López C. 2014. The reduction of plankton biomass induced by mesoscale stirring: A modeling study in the Benguela upwelling. Deep Sea Research I 83: 65-80

Hutchinson GE. 1961. The Paradox of the Plankton. The American Naturalist 95: 137-45

Hyrenbach KD, Veit RR, Weimerskirch H, Jr. GLH. 2006. Seabird associations with mesoscale eddies: the subtropical Indian Ocean. Marine Ecology Progress Series 324: 271-79

Jenkins WJ. 1988a. Nitrate flux into the euphotic zone near Bermuda. Nature 331: 521-23

Jenkins WJ. 1988b. The use of anthropogenic tritium and helium-3 to study subtropical gyre ventilation and circulation. Phil. Trans. Roy. Soc. 325: 43-61

Jenkins WJ, Goldman J. 1985. Seasonal oxygen cycling and primary production in the Sargasso Sea. Journal of Marine Research 43: 465-91

Johnson KS, Berelson WM, Boss ES, Chase Z, Claustre H, et al. 2009. Observing biogeochemical cycles at global scales with profiling floats and gliders: Prospects for a global array. Oceanography 22: 216-25

José YS, Aumont O, Machu E, Penven P, Moloney CL, Maury O. 2014. Influence of mesoscale eddies on biological production in the Mozambique Channel: Several contrasted examples from a coupled ocean-biogeochemistry model. Deep Sea Research II 100: 7993

Kahru M, Mitchell BG, Gille ST, Hewes CD, Holm-Hansen O. 2007. Eddies enhance biological production in the Weddell-Scotia Confluence of the Southern Ocean. Geophysical Research Letters 34: L14603

Killworth PD, Cipollini P, Uz BM, Blundell JR. 2004. Physical and biological mechanisms for planetary waves observed in satellite-derived chlorophyll. J. Geophys. Res. 109: C07002

Klein P, Hua BL. 1988. Mesoscale heterogeneity of the wind-driven mixed layer: Influence of a quasigeostrophic flow. J. Mar. Res. 46: 495-525

Klein P, Lapeyre G. 2009. The oceanic vertical pump induced by mesoscale and submesoscale turbulence. Annu. Rev. Mar. Sci. 2009: 351-75

Knauss JA. 1978. Introduction to Physical Oceanography. Englewood Cliffs, NJ: Prentice-Hall, Inc. $338 \mathrm{pp}$.

Kobayashi DR, Cheng I-J, Parker DM, Polovina JJ, Kamezaki N, Balazs GH. 2011. Loggerhead turtle (Caretta caretta) movement off the coast of Taiwan: characterization of a hotspot in the East China Sea and investigation of mesoscale eddies. ICES Journal of Marine Science: Journal du Conseil 68: 707-18 
1014

1015

1016

1017

1018

1019

1020

1021

1022

1023

1024

1025

1026

Kouketsu S, Tomita H, Oka E, Hosoda S, Kobayashi T, Sato K. 2012. The role of meso-scale eddies in mixed layer deepening and mode water formation in the western North Pacific. Journal of Oceanography 68: 63-77

Krause JW, Lomas MW, Nelson DM. 2009. Biogenic silica at the Bermuda Atlantic Time-series Study site in the Sargasso Sea: Temporal changes and their inferred controls based on a 15-year record. Global Biogeochemical Cycles 23: GB3004

Krause JW, Nelson DM, Lomas MW. 2010. Production, dissolution, accumulation, and potential export of biogenic silica in a Sargasso Sea mode-water eddy. Limnology \& Oceanography 55: 569-79

Kunze E. 1985. Near-inertial wave propagation in geostrophic shear. Journal of Physical Oceanography 15: 544-656

Lapeyre G, Klein P. 2006. Impact of the small-scale elongated filaments on the oceanic vertical pump. Journal of Marine Research 64: 835-51

Lee MM, Williams RG. 2000. The role of eddies in the isopycnic transfer of nutrients and their impact on biological production. Journal of Marine Research 58: 895-917

Legendre L, Demers S. 1984. Towards dynamic biological oceanography and limnology. Can. J. Fish. Aquat. Sci. 41: 2-19

Lehahn Y, d'Ovidio F, Lévy M, Amitai Y, Heifetz E. 2011. Long range transport of a quasi isolated chlorophyll patch by an Agulhas ring. Geophysical Research Letters 38: L16610

Lehahn Y, d'Ovidio F, Lévy M, Heifetz E. 2007. Stirring of the northeast Atlantic spring bloom: A Lagrangian analysis based on multisatellite data. Journal of Geophysical Research 112: $\mathrm{C} 08005$

Letelier RM, Karl DM, Abbott MR, Flament PJ, Freilich MH, Lukas R. 2000. Role of late winter mesoscale events in the biogeochemical variability of the upper water column of the North Pacific Subtropical Gyre. J. Geophys. Res. 105: 28,723-28,39

Lévy M. 2008. The Modulation of Biological Production by Oceanic Mesoscale Turbulence. In Transport and Mixing in Geophysical Flows, ed. J Weiss, A Provenzale, pp. 219-61: Springer Berlin Heidelberg

Lévy M, Ferrari R, Franks PJS, Martin AP, Rivière P. 2012a. Bringing physics to life at the submesoscale. Geophysical Research Letters 39: L14602

Lévy M, Iovino D, Resplandy L, Klein P, Madec G, et al. 2012b. Large-scale impacts of submesoscale dynamics on phytoplankton: Local and remote effects. Ocean Modelling 43-44: 77-93

Lévy M, Jahn O, Dutkiewicz S, Follows MJ. 2014. Phytoplankton diversity and community structure affected by oceanic dispersal and mesoscale turbulence. Limnology and Oceanography: Fluids and Environments 4: 67-84

Lévy M, Klein P. 2004. Does the low frequency variability of mesoscale dynamics explain a part of the phytoplankton and zooplankton spectral variability? Proceedings of the Royal Society of London A: Mathematical, Physical and Engineering Sciences 460: 1673-87

Lévy M, Klein P, Treguier A-M. 2001. Impact of sub-mesoscale physics on production and subduction of phytoplankton in an oligotrophic regime. J. Mar. Res. 59: 535-65

Lévy M, Martin AP. 2013. The influence of mesoscale and submesoscale heterogeneity on ocean biogeochemical reactions. Global Biogeochemical Cycles 27: 1139-50

Lévy M, Mémery L, Madec G. 1998. The onset of a bloom after deep winter convection in the northwestern Mediterranean sea: mesoscale process study with a primitive equation model. Journal of Marine Systems 16: 7-21 
1027

1028

1029

1030

1031

1032

1033

1034

1035

1036

1037

1038

1039

1040

1041

1042

1043

1044

1045

1046

1047

1048

1049

1050

1051

1052

1053

1054

1055

1056

1057

1058

1059

1060

1061

1062

1063

1064

1065

1066

1067

1068

1069

1070

1071

1072

Lévy M, Mémery L, Madec G. 1999. The onset of the Spring Bloom in the MEDOC area: mesoscale spatial variability. Deep Sea Research I 46: 1137-60

Lewis MR. 2002. Variability of Plankton and Plankton Processes on the Mesoscale. In Phytoplankton Productivity: Carbon Assimilation in Marine and Freshwater Ecosystems, ed. PJIB Williams, DN Thomas, CS Reynolds, pp. 141-55: Blackwell Science Ltd

Li J, Qi Y, Jing Z, Wang J. 2014. Enhancement of eddy-Ekman pumping inside anticyclonic eddies with wind-parallel extension: Satellite observations and numerical studies in the South China Sea. Journal of Marine Systems 132: 150-61

Lima ID, Olson DB, Doney SC. 2002. Biological response to frontal dynamics and mesoscale variability in oligotrophic environments: Biological production and community structure. Journal of Geophysical Research: Oceans 107: 25-1-25-21

Lindo-Atichati D, F. B, G. G, B. M, Muller-Karger FE, Habtes S. 2012. Varying mesoscale structures influence larval fish distribution in the northern Gulf of Mexico. Marine Ecology Progress Series 463: 245-57

Lobel PS, Robinson AR. 1986. Transport and entrapment of fish larvae by ocean mesoscale eddies and currents in Hawaiian waters. Deep-Sea Research 33: 483-500

Mackas DL, Denman KL, Abbott MR. 1985. Plankton patchiness: biology in the physical vernacular. Bull. Mar. Sci. 37: 652-74

Mahadevan A. 2016. Impact of Submesoscale Physics on Primary Productivity of Plankton. Annual Review of Marine Science 8: null

Mahadevan A, D’Asaro E, Lee C, Perry MJ. 2012. Eddy-Driven Stratification Initiates North Atlantic Spring Phytoplankton Blooms. Science 337: 54-58

Mahadevan A, Thomas LN, Tandon A. 2008. Comment on "Eddy/Wind Interactions Stimulate Extraordinary Mid-Ocean Plankton Blooms". Science 320: DOI: 10.1126/science. 1152111

Marshall D. 1997. Subduction of water masses in an eddying ocean. Journal of Marine Research 55: $201-22$

Martin AP. 2003. Phytoplankton patchiness: the role of lateral stirring and mixing. Progress In Oceanography 57: 125-74

Martin AP, Lévy M, van Gennip S, Pardo S, Srokosz M, et al. submitted. An observational assessment of the influence of mesoscale and submesoscale heterogeneity on ocean biogeochemical reactions. Global Biogeochemical Cycles

Martin AP, Pondaven P. 2003. On estimates for the vertical nitrate flux due to eddy pumping. Journal of Geophysical Research: Oceans 108: 3359

Martin AP, Richards KJ. 2001. Mechanisms for vertical nutrient transport within a North Atlantic mesoscale eddy. Deep-Sea Research II 48: 757-73

Martin AP, Richards KJ, Law CS, Liddicoat M. 2001. Horizontal dispersion within an anticyclonic mesoscale eddy. Deep Sea Research II 48: 739-55

McGillicuddy DJ. 2011. Eddies Masquerade as Planetary Waves. Science 334: 318-19

McGillicuddy DJ. 2015. Formation of Intra-thermocline Lenses by Eddy-wind Interaction. Journal of Physical Oceanography 45: 606-12

McGillicuddy DJ, Anderson LA, Bates NR, Bibby T, Buesseler KO, et al. 2007. Eddy/wind interactions stimulate extraordinary mid-ocean plankton blooms. Science 316: 1021-26

McGillicuddy DJ, Anderson LA, Doney SC, Maltrud ME. 2003. Eddy-driven sources and sinks of nutrients in the upper ocean: Results from a $0.1^{\circ}$ resolution model of the North Atlantic. Global Biogeochemical Cycles 17: 1035 doi:10.29/2002GB001987 
1073

1074

1075

1076

1077

1078

1079

1080

1081

1082

1083

1084

1085

1086

1087

1088

1089

1090

1091

1092

1093

1094

1095

1096

1097

1098

1099

1100

1101

1102

1103

1104

1105

1106

1107

1108

1109

1110

1111

1112

1113

1114

1115

1116

1117

1118

McGillicuddy DJ, Robinson A, Siegel D, Jannasch HW, Johnson R, et al. 1998. Influence of mesoscale eddies on new production in the Sargasso Sea. Nature 394: 263-65

McGillicuddy DJ, Robinson AR. 1997. Eddy induced nutrient supply and new production in the Sargasso Sea. Deep-Sea Research I 44: 1427-49

McGillicuddy DJ, Robinson AR, McCarthy JJ. 1995. Coupled physical and biological modeling of the spring bloom in the North Atlantic: (II) Three dimensional bloom and post-bloom effects. Deep-Sea Research 42: 1359-98

McNeil JD, Jannasch HW, Dickey TD, McGillicuddy DJ, Brzezinski M, Sakamoto CM. 1999. New chemical, bio-optical and physical observations of upper ocean response to the passage of a mesoscale eddy off Bermuda. J. Geophys. Res. 104: 15537-48

McWilliams JC. 2008. The Nature and Consequences of Oceanic Eddies. In Ocean Modeling in an Eddying Regime, pp. 5-15: American Geophysical Union

Mémery L, Reverdin G, Paillet J, Oschlies A. 2005. Introduction to the POMME special section: Thermocline ventilation and biogeochemical tracer distribution in the northeast Atlantic Ocean and impact of mesoscale dynamics. Journal of Geophysical Research: Oceans 110: C07S01

Menkes CE, Kennan SC, Flament P, Dandonneau Y, Masson S, et al. 2002. A whirling ecosystem in the equatorial Atlantic. Geophysical Research Letters 29: 1-4

Miller LA, Robert M, Crawford WR. 2005. The large, westward-propagating Haida Eddies of the Pacific eastern boundary. Deep Sea Research II 52: 845-51

Mitarai S, Siegel DA, Watson JR, Dong C, McWilliams JC. 2009. Quantifying connectivity in the coastal ocean with application to the Southern California Bight. Journal of Geophysical Research: Oceans 114: C10026

Mizobata K, Saitoh SI, Shiomoto A, Miyamura T, Shiga N, et al. 2002. Bering Sea cyclonic and anticyclonic eddies observed during summer 2000 and 2001. Progress In Oceanography 55: $65-75$

Moore TS, Matear RJ, Marra J, Clementson L. 2007. Phytoplankton variability off the Western Australian Coast: Mesoscale eddies and their role in cross-shelf exchange. Deep Sea Research II 54: 943-60

Nel DC, Lutjeharms JRE, Pakhomov EA, Ansorge IJ, Ryan PG, Klages NTW. 2001. Exploitation of mesoscale oceanographic features by grey-headed albatross Thalassarche chrysostoma in the southern Indian Ocean. Marine Ecology Progress Series 217: 15-26

Nelepo BA, ed. 1983. Experimental investigations under the international POLYMODE program. New Delhi: Oxonian Press. 143 pp.

Nelson DM, McCarthy JJ, Joyce TM, Ducklow HW. 1989. Enhanced near-surface nutrient availability and new production resulting from the frictional decay of a Gulf 0 Stream warm-core ring. Deep-Sea Research 36: 705-14

Niiler PP. 1969. On the Ekman divergence in an oceanic jet. Journal of Geophysical Research 74: 7048-52

Nurser AJG, Zhang JW. 2000. Eddy-induced mixed layer shallowing and mixed layer/thermocline exchange. Journal of Geophysical Research: Oceans 105: 21851-68

Olaizola M, Ziemann DA, Bienfang PK, Walsh WA, Conquest LD. 1993. Eddy-induced oscillations of the pycnocline affect the floristic composition and depth distribution of phytoplankton in the subtropical Pacific. Marine Biology V116: 533-42

Olson DB, Backus RH. 1985. The concentrating of organisms at fronts: A cold-water fish and a warm-core Gulf Stream ring. J. Mar. Res. 43: 113-37 
Oschlies A. 2002. Can eddies make ocean deserts bloom? Global Biogeochem. Cycles 16: 1106 Oschlies A. 2008. Eddies and Upper-Ocean Nutrient Supply. In Ocean Modeling in an Eddying Regime, pp. 115-30: American Geophysical Union

Oschlies A, Garcon VC. 1998. Eddy-induced enhancement of primary production in a model of the North Atlantic Ocean. Nature 394: 266-69

Pascual A, Faugère Y, Larnicol G, LeTraon PY. 2006. Improved description of the ocean mesoscale variability by combining four satellite altimeters. Geophys. Res. Lett. 33: L02611

Pasquero C, Bracco A, Provenzale A. 2005. Impact of the spatiotemporal variability of the nutrient flux on primary productivity in the ocean. Journal of Geophysical Research: Oceans 110: C07005

Pearce AF, Griffiths RW. 1991. The mesoscale structure of the Leeuwin Current: A comparison of laboratory models and satellite imagery. Journal of Geophysical Research: Oceans 96: 16739-57

Perruche C, Rivière P, Lapeyre G, Carton X, Pondaven P. 2011. Effects of surface quasigeostrophic turbulence on phytoplankton competition and coexistence. Journal of Marine Research 69: 105-35

Pingree RD, Holligan PM, Mardell GT. 1979. Phytoplankton growth and cyclonic eddies. Nature 278: $245-47$

Polovina JJ, Balazs GH, Howell EA, Parker DM, Seki MP, Dutton PH. 2004. Forage and migration habitat of loggerhead (Caretta caretta) and olive ridley (Lepidochelys olivacea) sea turtles in the central North Pacific Ocean. Fisheries Oceanography 13: 3651

Prasanna Kumar S, Nuncio M, Ramaiah N, Sardesai S, Narvekar J, et al. 2007. Eddy-mediated biological productivity in the Bay of Bengal during fall and spring intermonsoons. Deep Sea Research I 54: 1619-40

Provenzale A. 1999. Transport by coherent barotropic vortices. Annual Review of Fluid Mechanics 31: 55-93

Radchenko LA. 1983. Quantitative distribution of seston in the region. In Experimental investigations under the international POLYMODE program, ed. BA Nelepo, pp. 129-35. New Delhi: Oxonian Press

Resplandy L, Lévy M, Madec G, Pous S, Aumont O, Kumar D. 2011. Contribution of mesoscale processes to nutrient budgets in the Arabian Sea. Journal of Geophysical Research: Oceans 116: C11007

Richardson DE, Llopiz JK, Guigand CM, Cowen RK. 2010. Larval assemblages of large and medium-sized pelagic species in the Straits of Florida. Progress In Oceanography 86: 820

Ring Group. 1981. Gulf Stream cold-core rings: their physics, chemistry and biology. Science 212: $1091-100$

Rodriguez J, Tintore J, Allen JT, Blanco JM, Gomis D, et al. 2001. Mesoscale vertical motion and the size structure of phytoplankton in the ocean. Nature 410: 360-63

Rossi V, López C, Sudre J, Hernández-García E, Garçon V. 2008. Comparative study of mixing and biological activity of the Benguela and Canary upwelling systems. Geophysical Research Letters 35: L11602 
1163

1164

1165

1166

1167

1168

1169

1170

1171

1172

1173

1174

1175

1176

1177

1178

1179

1180

1181

1182

1183

1184

1185

1186

1187

1188

1189

1190

1191

1192

1193

1194

1195

1196

1197

1198

1199

1200

1201

1202

1203

1204

1205

1206

1207

1208

Roukhiyainen MI, Yunev OA. 1983. Phytoplankton and primary productin in the wester Sargasso Sea in summer 1977. In Experimental investigations under the international POLYMODE program, ed. BA Nelepo, pp. 120-28. New Delhi: Oxonian Press

Savidge G, Williams PJIB. 2001. The PRIME 1996 cruise: an overview. Deep-Sea Research II 48: 687-704

Seki MP, Lumpkin R, Flament P. 2002. Hawaii Cyclonic Eddies and Blue Marlin Catches: The Case Study of the 1995 Hawaiian International Billfish Tournament. Journal of Oceanography 58: 739-45

Seki MP, Polovina JJ, Brainard RE, Bidigare RR, Leonard CL, Foley DG. 2001. Biological enhancement at cyclonic eddies tracked with GOES Thermal Imagery in Hawaiian waters. Geophysical Research Letters 28: 1583-86

Shulenberger E, Reid JL. 1981. The Pacific shallow oxygen maximum, deep chlorophyll maximum, and primary productivity, reconsidered. Deep-Sea Res. 28A: 901-19

Siegel DA, Court DB, Menzies DW, Peterson P, Maritorena S, Nelson NB. 2008. Satellite and in situ observations of the bio-optical signatures of two mesoscale eddies in the Sargasso Sea. Deep-Sea Research II 55: 1218-30

Siegel DA, Peterson P, McGillicuddy DJ, Jr., Maritorena S, Nelson NB. 2011. Bio-optical footprints created by mesoscale eddies in the Sargasso Sea. Geophys. Res. Lett. 38: L13608

Srokosz MA, Martin AP, Fasham MJR. 2003. On the role of biological dynamics in plankton patchiness at the mesoscale: An example from the eastern North Atlantic Ocean. Journal of Marine Research 61: 517-37

Stern ME. 1965. Interaction of a uniform wind stress with a geostrophic vortex. Deep-Sea Research 12: 355-67

Stramma L, Bange HW, Czeschel R, Lorenzo A, Frank M. 2013. On the role of mesoscale eddies for the biological productivity and biogeochemistry in the eastern tropical Pacific Ocean off Peru. Biogeosciences 10: 7293-306

Strass VH. 1992. Chlorophyll patchiness caused by mesoscale upwelling at fronts. Deep-Sea Res. 39: 75-96

Sweeney EN, McGillicuddy DJ, Buesseler KO. 2003. Biogeochemical impacts due to mesoscale eddy activity in the Sargasso Sea as measured at the Bermuda Atlantic Time Series (BATS) site. Deep-Sea Res. II 50: 3017-39

Teo SLH, Block BA. 2010. Comparative Influence of Ocean Conditions on Yellowfin and Atlantic Bluefin Tuna Catch from Longlines in the Gulf of Mexico. PLoS ONE 5: e10756

Ternon JF, Bach P, Barlow R, Huggett J, Jaquemet S, et al. 2014. The Mozambique Channel: From physics to upper trophic levels. Deep Sea Research II 100: 1-9

Tew Kai E, Marsac F. 2010. Influence of mesoscale eddies on spatial structuring of top predators' communities in the Mozambique Channel. Progress In Oceanography 86: 214-23

Uz BM, Yoder JA, Osychny V. 2001. Pumping of nutrients to ocean surface waters by the action of propagating planetary waves. Nature 409: 597-600

Vaillancourt RD, Marra J, Seki MP, Parsons ML, Bidigare RR. 2003. Impact of a cyclonic eddy on phytoplankton community structure and photosynthetic competency in the subtropical North Pacific Ocean. Deep Sea Research I 50: 829-47

Venrick EL. 1990. Mesoscale patterns of chlorophyll $a$ in the central North Pacific. Deep-Sea Research 37: 1017-31 
Waite AM, Thompson PA, Pesant S, Feng M, Beckley LE, et al. 2007. The Leeuwin Current and its eddies: An introductory overview. Deep Sea Research II 54: 789-96

Wallhead PJ, Garçon VC, Martin AP. 2013. Efficient upscaling of ocean biogeochemistry. Ocean Modelling 63: 40-55

Wallhead PJ, Martin AP, Srokosz MA. 2008. Spatially implicit plankton population models: transient spatial variability. Journal of Theoretical Biology 253: 405-23

Warm Core Rings Executive Committee. 1982. Multidisciplinary program to study warm core rings. Eos, Transactions American Geophysical Union 63: 834-35

Weimerskirch H, Corre ML, Jaquemet Sb, Potier M, Marsac F. 2004. Foraging strategy of a top predator in tropical waters: great frigatebirds in the Mozambique Channel. Marine Ecology Progress Series 275: 297-308

Wiebe PH, Flierl GR. 1983. Euphausiid invasion / dispersal in Gulf Stream cold-core rings. Australian Journal of Marine and Freshwater Research 34: 625-52

Wiebe PH, Joyce TM. 1992. Introduction to interdisciplinary studies of Kuroshio and Gulf Stream Rings. Deep-Sea Research 39: S1-S6

Wiebe PH, McDougall TJ. 1986. Introduction to a collection of papers on warm-core rings. Deep Sea Research 33: 1455-57

Williams RG. 1988. Modification of ocean eddies by air-sea interaction. Journal of Geophysical Research: Oceans 93: 15523-33

Williams RG, Follows MJ. 1998. The Ekman transfer of nutrients and maintenance of new production over the North Atlantic. Deep-Sea Research I 45: 461-89

Williams RG, Follows MJ. 2003. Physical transport of nutrients and the maintenance of biological production. In Ocean Biogeochemistry: The Role of the Ocean Carbon Cycle in Global Change, ed. MJR Fasham, pp. 19-51. Berlin: Springer-Verlag

Williams RG, Follows MJ. 2011. Ocean dynamics and the carbon cycle: principles and mechanisms. Cambridge, UK: Cambridge University Press. 404 pp.

Woods JD. 1988. Mesoscale upwelling and primary production. In Toward a Theory on Biological-Physical Interactions in the World Ocean, ed. BJ Rothschild, pp. 7-23. Dordrecht: D. Reidel

Xiu P, Chai F. 2011. Modeled biogeochemical responses to mesoscale eddies in the South China Sea. Journal of Geophysical Research: Oceans 116: C10006

Xiu P, Palacz AP, Chai F, Roy EG, Wells ML. 2011. Iron flux induced by Haida eddies in the Gulf of Alaska. Geophysical Research Letters 38: L13607

Yoda K, Shiomi K, Sato K. 2014. Foraging spots of streaked shearwaters in relation to ocean surface currents as identified using their drift movements. Progress In Oceanography 122: $54-64$

Yoshimori A, Kishi MJ. 1994. Effects of interaction between two warm-core rings on phytoplankton distribution. Deep Sea Research I 41: 1039-52

Zhou K, Dai M, Kao S-J, Wang L, Xiu P, et al. 2013. Apparent enhancement of 234Th-based particle export associated with anticyclonic eddies. Earth and Planetary Science Letters 381: 198-209 
1255

1256

1257

1258

1259

1260

1261

1262

\begin{tabular}{|l|c|c|c|}
\hline Eddy type & MLD anomaly & \multicolumn{2}{|c|}{ CHL anomaly } \\
\hline & & Nutrient limited & Light limited \\
\hline Cyclone & - & - & + \\
\hline Anticyclone & + & + & - \\
\hline
\end{tabular}

Table 1. Upper ocean chlorophyll (CHL) anomalies expected from anomalies in mixed layer depth (MLD) associated with cyclones and anticyclones in different regimes limited by nutrients and light. Note this idealized summary does not represent mode-water eddies, which constitute a special case of anticyclones.

\begin{tabular}{|l|l|l|}
\hline Program & Area & Reference \\
\hline POLYMODE & Sargasso Sea & Nelepo (1983) \\
\hline Cold Core Rings & Gulf Stream & Ring Group (1981) \\
\hline Warm Core Rings & $\begin{array}{l}\text { Gulf Stream, Kuroshio, East Australia } \\
\text { Current }\end{array}$ & $\begin{array}{l}\text { Wiebe \& McDougall (1986) } \\
\text { Wiebe and Joyce (1992) }\end{array}$ \\
\hline PRIME & Northeast Atlantic & Savidge \& Williams (2001) \\
\hline POMME & Northeast Atlantic & Mémery et al. (2005) \\
\hline $\begin{array}{l}\text { Haida Eddy } \\
\text { Project }\end{array}$ & Gulf of Alaska & Miller et al. (2005) \\
\hline Eddies 2003 & Leeuwin Current & Waite et al. (2007) \\
\hline E-FLUX & Hawaiian lee eddies & $\begin{array}{l}\text { Benitez-Nelson \& McGillicuddy } \\
(2008)\end{array}$ \\
\hline EDDIES & Sargasso Sea & $\begin{array}{l}\text { Benitez-Nelson \& McGillicuddy } \\
(2008)\end{array}$ \\
\hline MESOBIO & Mozambique Channel & Ternon (2014) \\
\hline
\end{tabular}

1264 Supplementary Table. Interdisciplinary in situ process studies of mesoscale eddies. Please

1265 forward information on additional studies that should be included to dmcgillicuddy@whoi.edu

1266 so that the living document located at

1267 http://science.whoi.edu/users/mcgillic/eddy process studies/table.pdf can be made more

1268 complete and kept current.

1269 


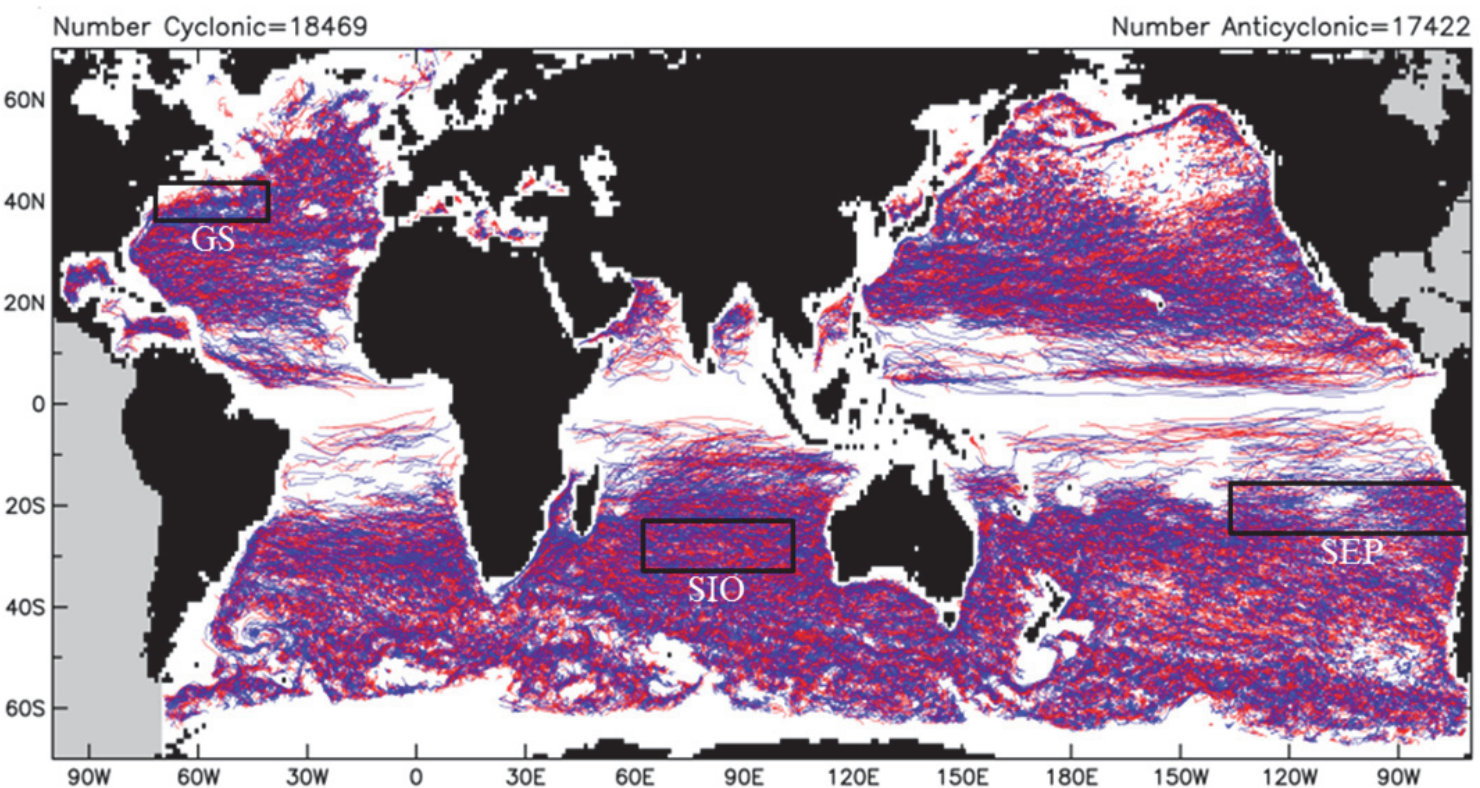

1274

Figure 1. Tracks of long-lived (lifetimes $\geq 16$ weeks) mesoscale eddies identified by an automated eddy tracking procedure (Chelton et al. 2011b). Red tracks represent anticyclones and blue tracks cyclones. Three regional subdomains are indicated: Southeast Pacific (SEP), the (2011b), courtesy of Peter Gaube. 


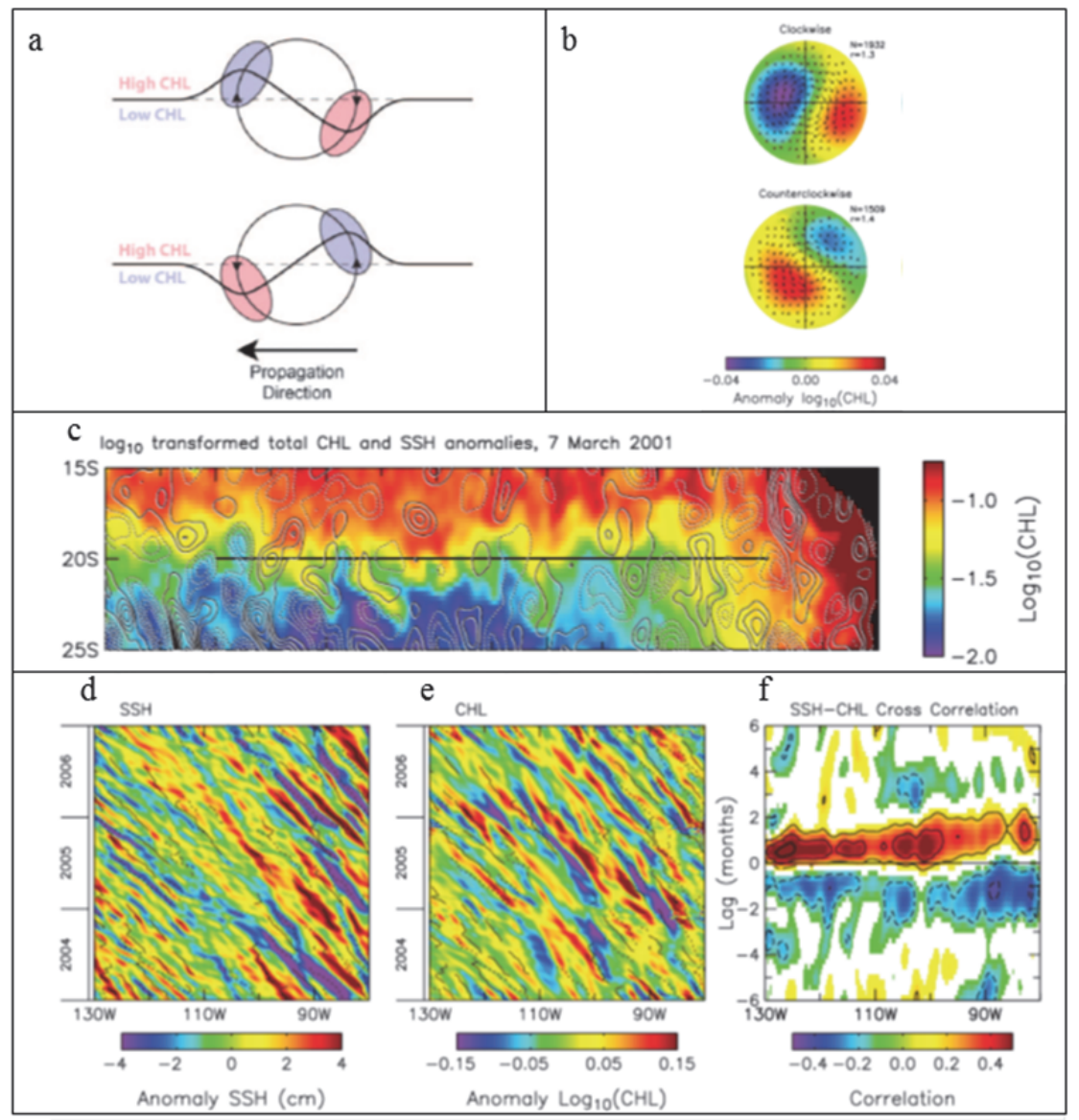

Figure 2. (a) Schematic diagram of eddy-driven stirring of CHL for clockwise (top) and counterclockwise (bottom) rotating eddies propagating westward in regions where the CHL gradient is northward. An otherwise smooth contour of CHL (dashed lines) is distorted by the rotational velocity field within the eddy, as shown by the solid lines. Advection of CHL within the large-scale background CHL gradient results in the positive and negative CHL anomalies shown by the red and purple regions, respectively. (b) Composite averages for clockwise (top) and counter-clockwise (bottom) eddies in the region labeled "SEP" in Figure 1. The outer perimeter of each circle corresponds to twice the eddy radius scale. The vectors in each panel are the gradient of the composite average $\mathrm{SSH}$, which is proportional to the geostrophic velocity. The number $\mathrm{N}$ of eddy realizations in the composite average and the magnitude $r$ of the ratio of the primary pole in the leading (left) half of each composite to the secondary pole in the trailing (right) half are labeled on each panel. (c) An example map from the SEP region for 7 March 2001 showing $\log _{10}(\mathrm{CHL})$ in color with contours of positive and negative anomaly $\mathrm{SSH}$ (solid and dashed lines, respectively) at intervals of $2 \mathrm{~cm}$, excluding the zero contour. The horizontal line indicates the section along which the time-longitude plots in panels $\mathrm{d}$ and e are presented. (d) SSH with eddy tracks within $\pm 2^{\circ}$ of $20^{\circ} \mathrm{S}$ overlaid (dashed and solid lines for $\mathrm{CW}$ and $\mathrm{CC}$ rotating eddies, respectively); (e) $\log 10(\mathrm{CHL})$ with the same eddy tracks overlaid. (f) Lagged cross-correlation between $\log _{10}(\mathrm{CHL})$ at time $\mathrm{t}$ and SSH at time $\mathrm{t}+\mathrm{lag}$, calculated over the full 10-year data record; the white areas correspond to correlations smaller than the estimated $95 \%$ significance level. Positive lags correspond to $\log _{10}(\mathrm{CHL})$ leading $\mathrm{SSH}$, and the contour interval is 0.2 with the zero contour omitted for clarity. From Chelton et al. (2011a). 
(a) Gulf Stream Ring Formation

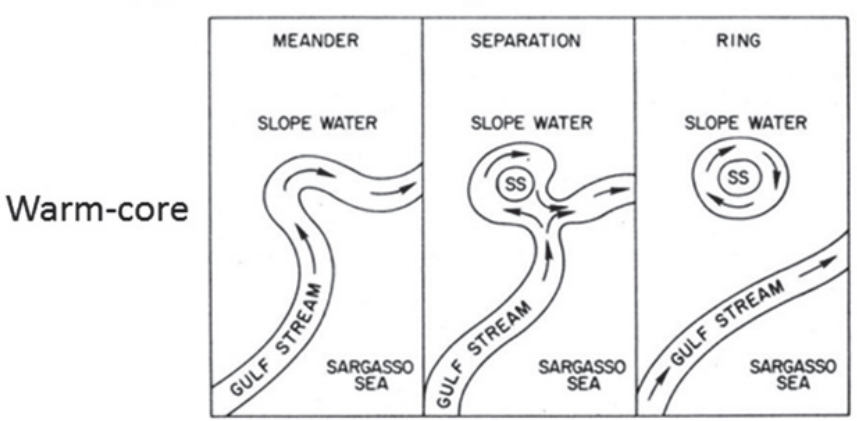

1303 1304 1305 1306 1307 1308 1309 1310

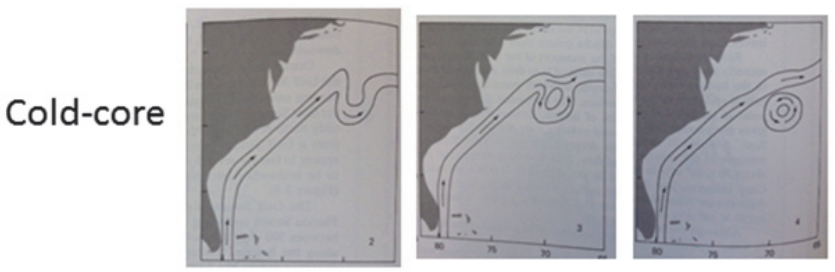
Pearce and Griffiths (1991). (b) Leeuwin Eddy Formation

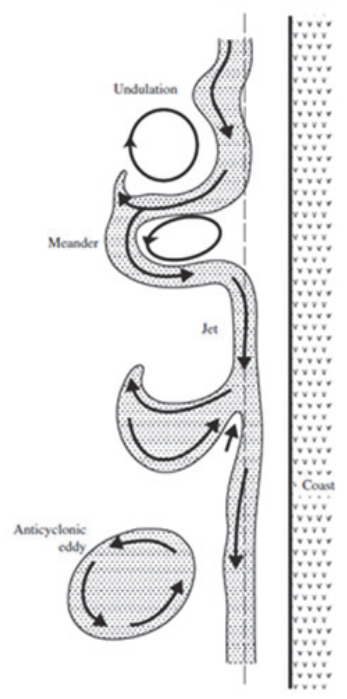

Figure 3. Processes of (a) Gulf Stream Ring formation, and (b) anticyclone generation in the Leeuwin current. Panel (a): (top) adapted from The Warm Core Rings Executive Committee (1982), bottom adapted from Knauss (1978); panel (b) adapted from Moore et al. (2007) and 
Anticyclones

(a)

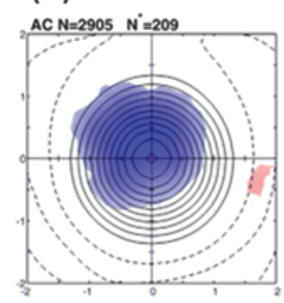

(b)

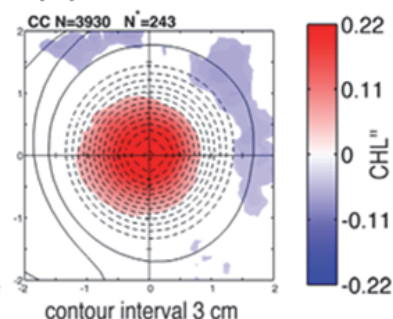

$\mathrm{SSH}$

(c)

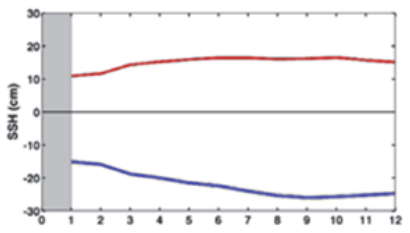

(d)

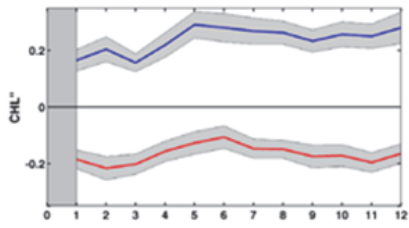

\section{South Indian Ocean}

(e)

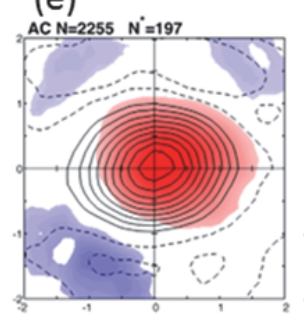

(f)

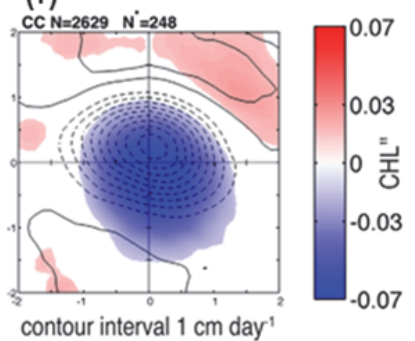

(g)

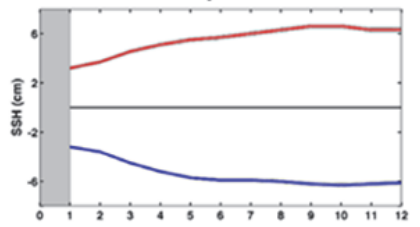

Eddy age (weeks) (h)

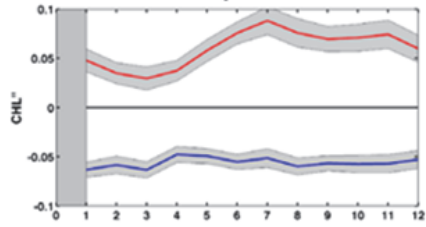

Eddy age (weeks)

Figure 4. Composite averages of eddy-centric CHL anomaly in $(\mathrm{a}, \mathrm{b})$ the Gulf Stream region (year round), and (e,f) the South Indian Ocean (May-October). Locations of the two domains are shown in Figure 1. Contours in panels (a) and (b) are SSH anomaly, and eddy-induced Ekman pumping in panels (e) and (f). Regions of the composites that do not exceed the $95 \%$ confidence interval of mean are masked with white. The $\mathrm{x}$ and $\mathrm{y}$ coordinates of the composite averages are normalized by the eddy radius. The title of each composite average indicates both the number of eddy realizations $\mathrm{N}$ used to construct the composite and the effective degrees of freedom $\mathrm{N}^{*}$ used to computed the $95 \%$ confidence interval. Right hand panels depict time-series of eddy amplitude and CHL anomaly for cyclones (blue) and anticyclones (red). The beginning of the time series are shaded to indicate that both eddy amplitude and CHL anomaly are only observed after the eddy is first detected by the automated eddy tracking procedure, defined here as week 1. From Gaube et al. (2014). 
Formation/ Intensification
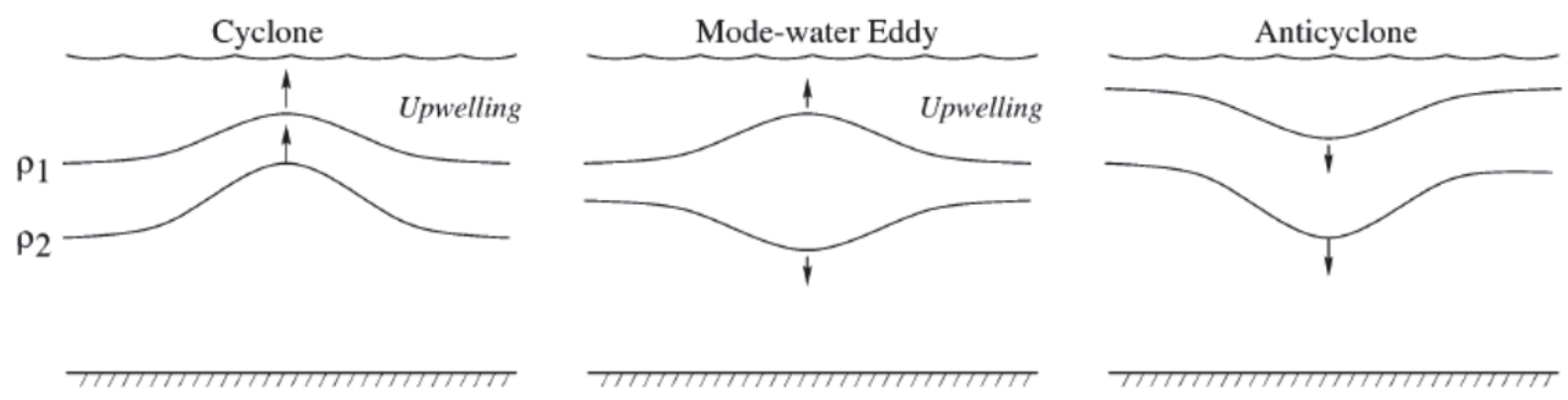

\section{Decay/ Relaxation}
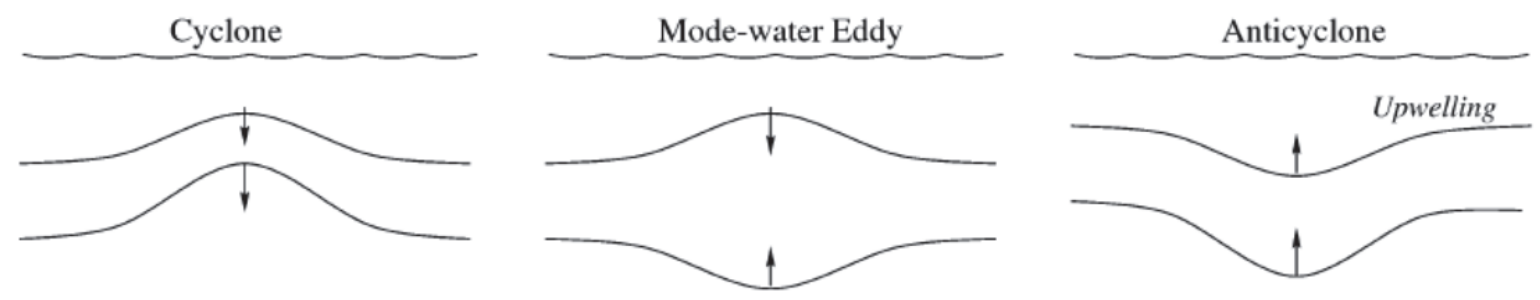

Figure 5. Isopycnal displacements associated with three types of eddies in the process of formation/intensification (top row) and decay (bottom row). Two density surfaces are depicted in each case: one in the seasonal thermocline $\left(\boldsymbol{\rho}_{\mathbf{1}}\right)$ and one in the main thermocline $\left(\boldsymbol{\rho}_{\mathbf{2}}\right)$. From 
(a)

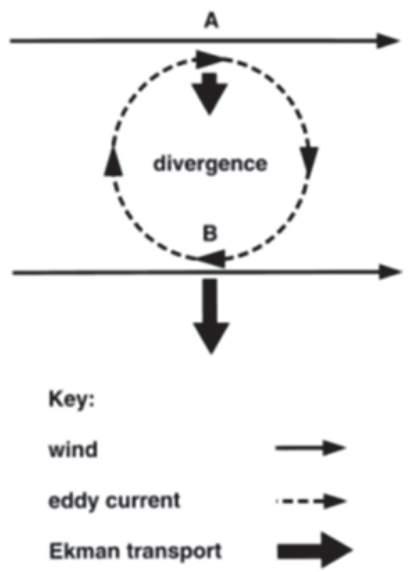

(b)

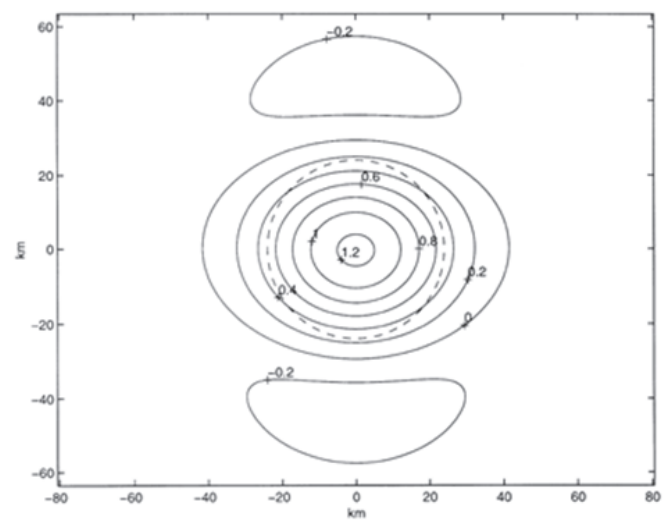

1334

1335

1336

1337

1338

1339

1340

1341

1342

1343

1344

1345

1346

Figure 6. (a) Illustration of how a uniform wind applied to an anticyclonic eddy can lead to a divergence and upwelling in the eddy interior. The surface current reduces the stress where the wind is in the same direction as the current (point A), and increases it where the wind and current oppose each other (point B). The difference in the magnitude of the associated Ekman transport creates a divergence at eddy center, regardless of the direction of the wind. (b) Vertical velocity field at the base of the Ekman layer for an idealized circular eddy subject to a $15 \mathrm{~m} \mathrm{~s}^{-1}$ wind. Contour intervals are $0.2 \mathrm{~m} \mathrm{~d}^{-1}$ with positive values denoting upwelling. The dotted line corresponds to the radius at which the maximum azimuthal velocity occurs. From Martin and Richards (2001). 


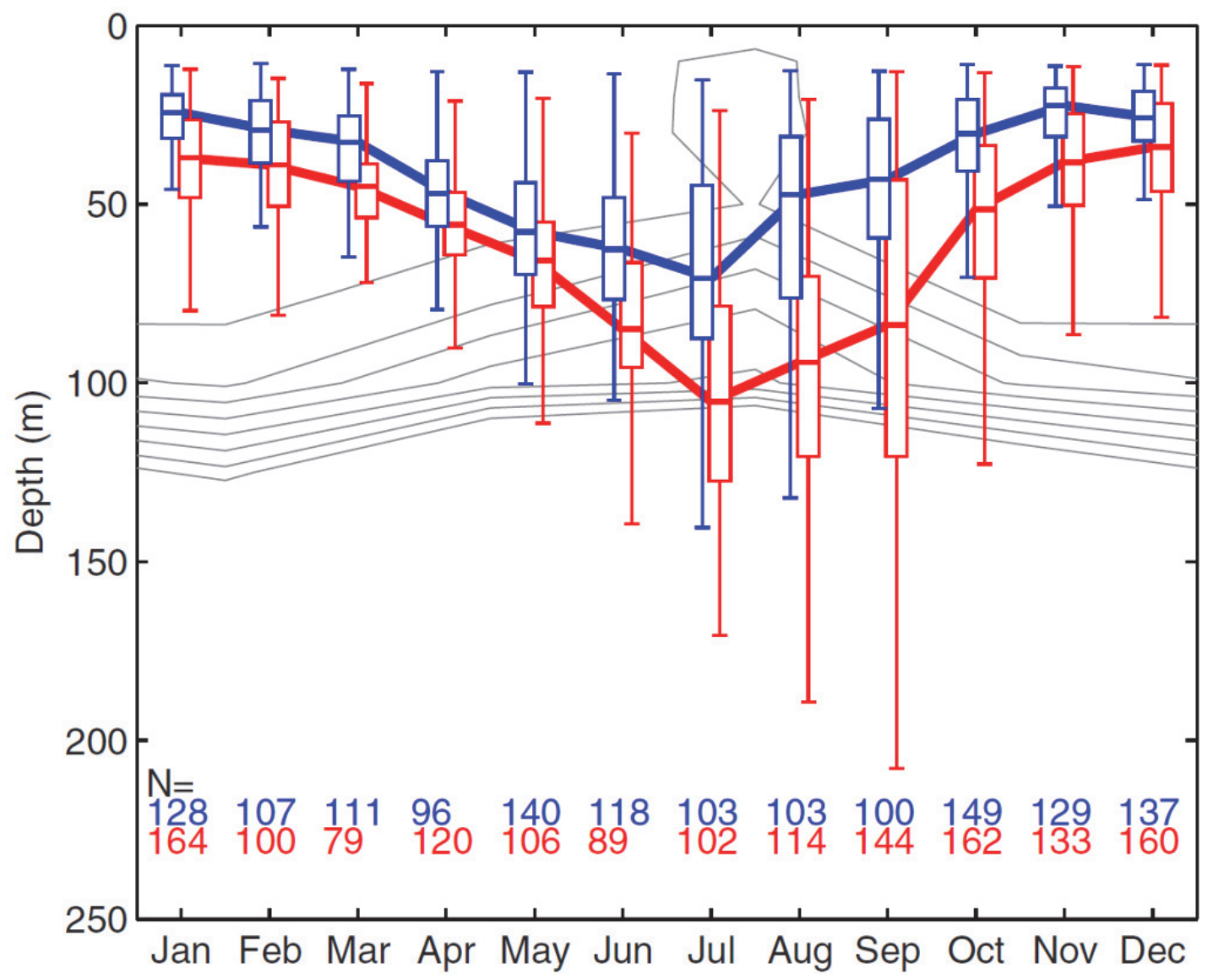

1347

1348

1349

1350

1351

1352

1353

1354

1355

1356

1357

Figure 7. Climatological average mixed layer depths in cyclonic (blue) and anticyclonic (red) eddy interiors from ARGO floats in the South Indian Ocean (region similar to "SIO" in Figure 1). The number $\mathrm{N}$ of $\mathrm{ARGO}$ floats used for each month is reported. The thin gray lines correspond to the $\mathrm{NO}_{3}$ mean seasonal contours (from World Ocean Atlas 2009) ranging from 0.3 to $1 \mathrm{mmol} \mathrm{m}^{-3}$. For each time point, the rectangular box is delimited by the lower quartile (Q1) and the upper quartile $(\mathrm{Q} 3)$, while the median is represented inside the box by a straight line. Whiskers are drawn to the extreme values that are inside the fences lying at Q1-1.5 X (Q3-Q1) and Q3+1.5 X (Q3-Q1). Lines join median values. From Dufois et al. (2014). 


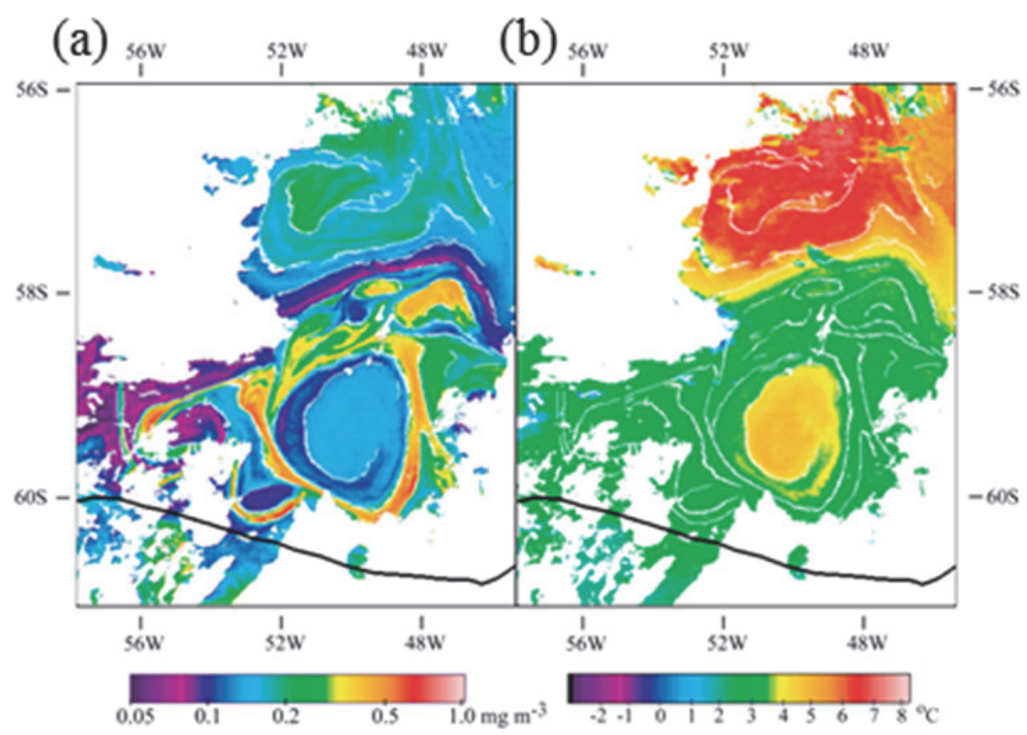

(c)

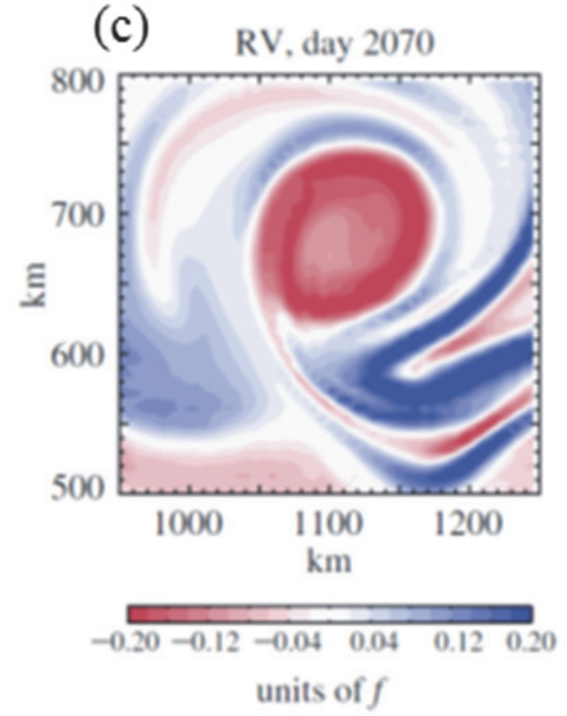

(d)

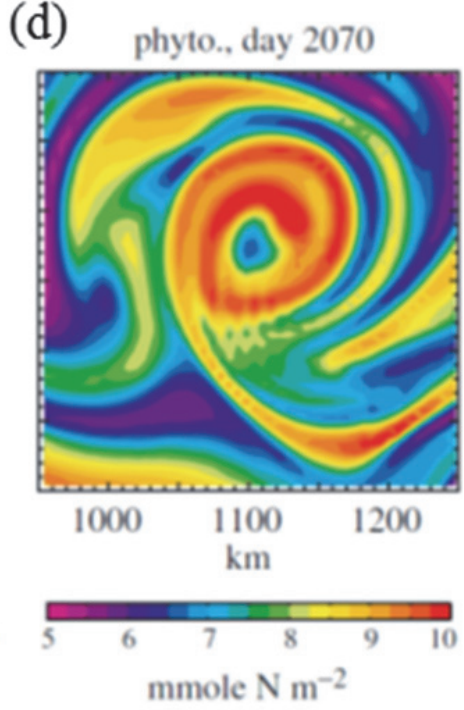

1360 Figure 8. A large anticyclonic eddy north of the mean position of the Southern Antarctic 1361 Circumpolar Current front (black curve) on Jan 28, 2004: (a) CHL and (b) sea surface 1362 temperature. Ocean areas covered by clouds are shown in white. The white curves are edges determined on the CHL image but overlaid on both images. Lower panels show output from a numerical model highlighting an anticyclonic eddy. Negative relative vorticity in panel (c) is accompanied by high phytoplankton concentration around the periphery of the vortex (d). Note that the sense of rotation is clockwise in the lower panels (northern hemisphere) and counterclockwise in the upper panels (southern hemisphere). Panels (a) and (b) from Kahru et al. (2007); panels (c) and (d) from Lévy \& Klein (2004). 


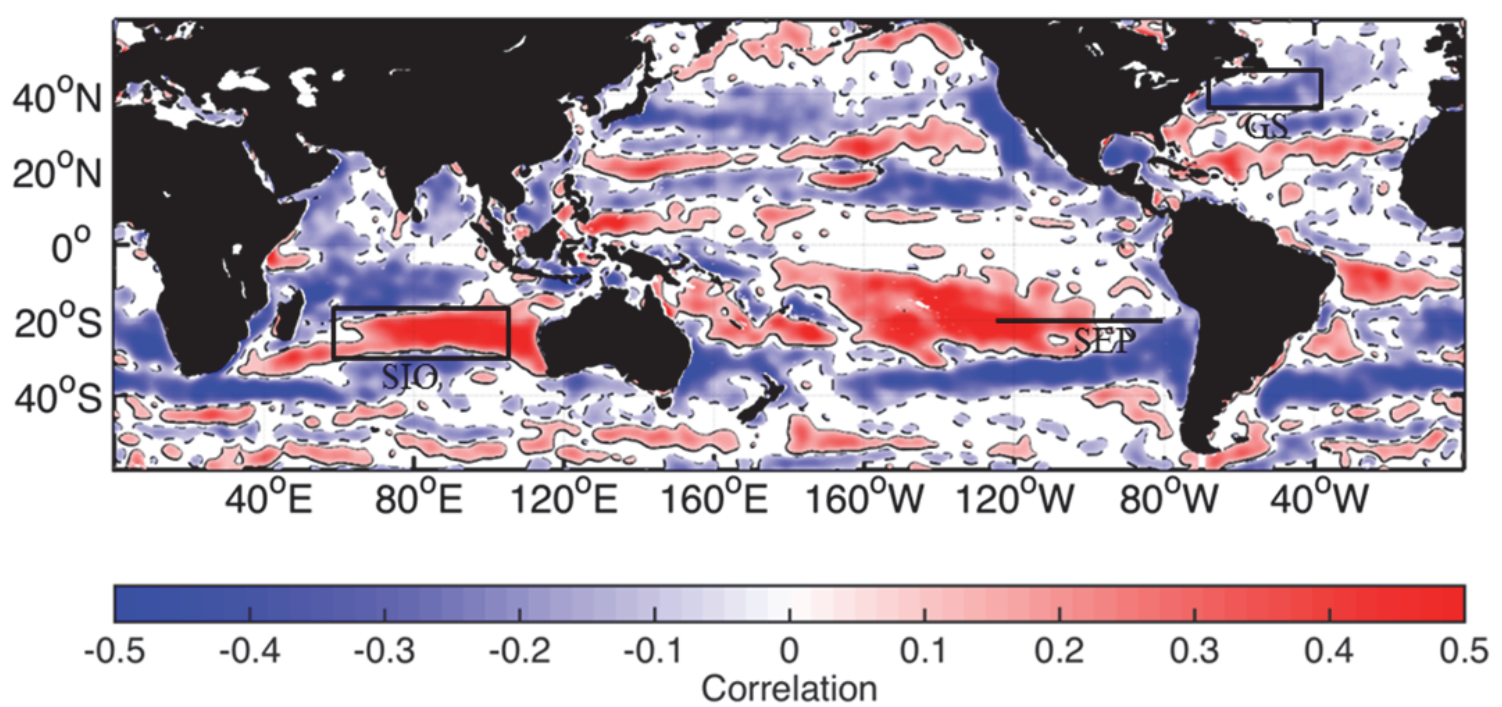

1371

1372

1373

1374

1375

1376
Figure 9. Map of the correlation between anomalies of sea level and chlorophyll. White areas correspond to correlations smaller than the estimated $95 \%$ significance level. Regions of significantly positive and negative cross correlations are enclosed by solid and dashed contours, respectively. Adapted from Gaube et al. (2014). 
a) eddy transfer

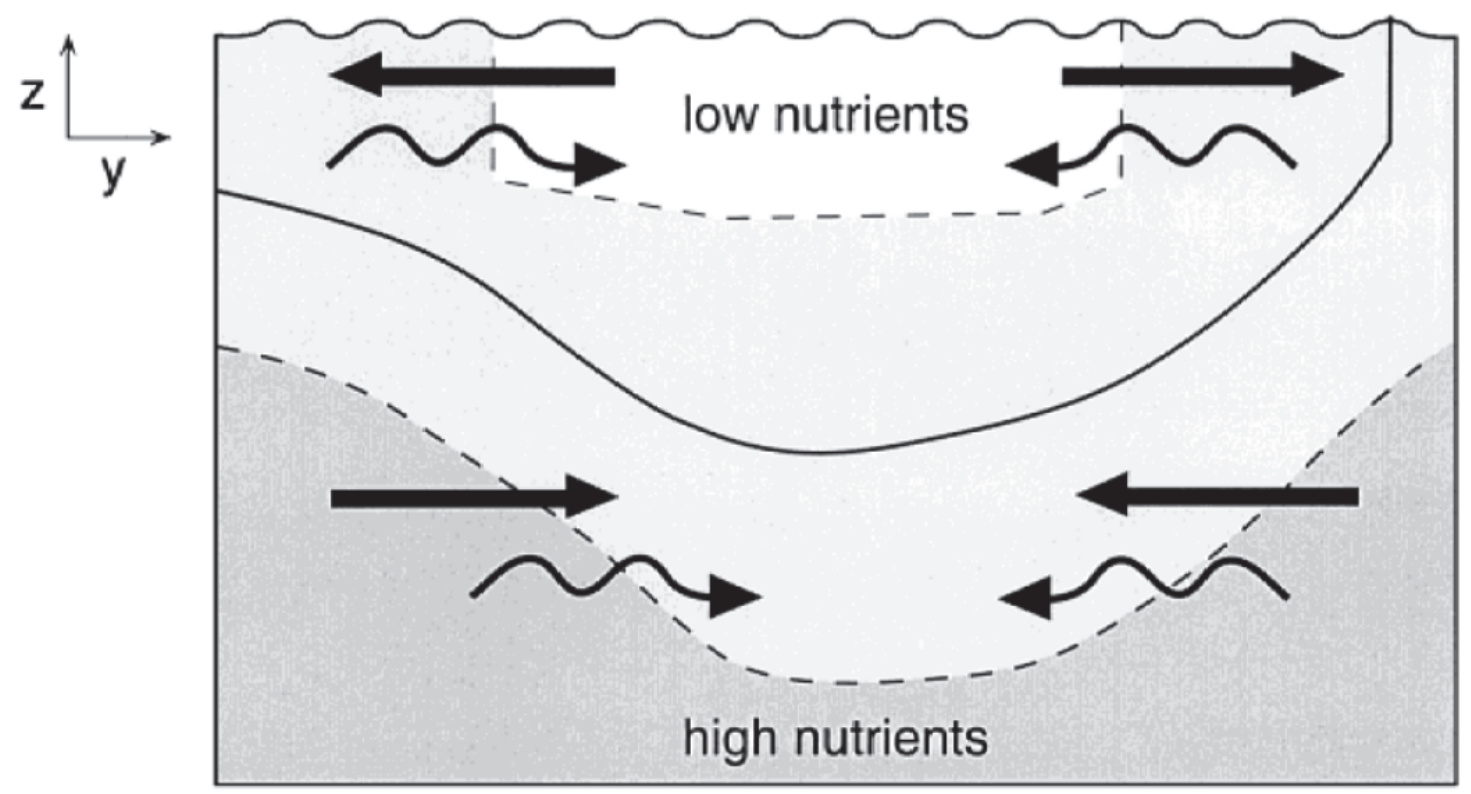

b) eddy and Ekman transfer

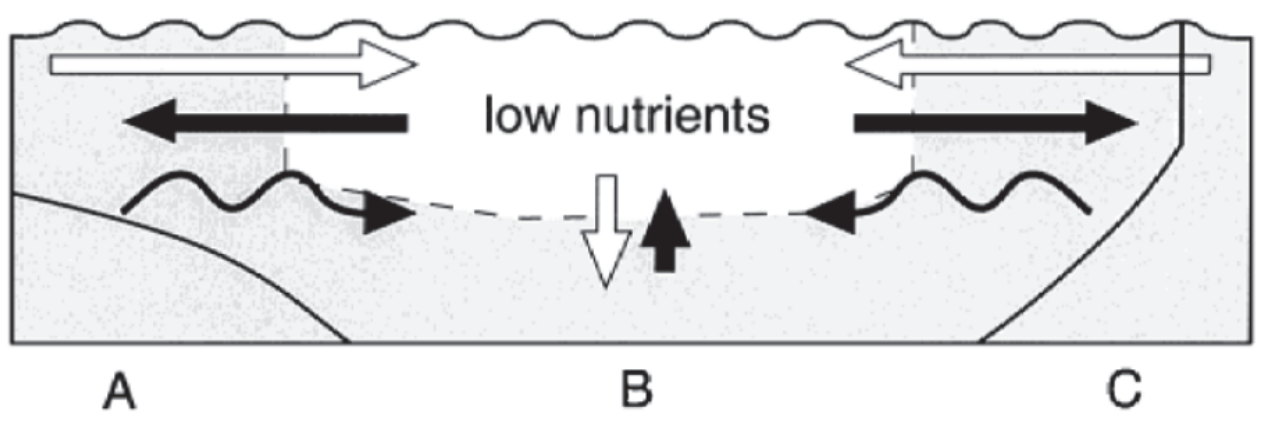

Figure 10. Schematic of the eddy-induced transfer of nutrients. SectionAC may be viewed as passing through a subtropical gyre or section $A B$ as through the Southern Ocean. In (a), the eddy-induced advection (black straight arrows) and diffusion (curly arrows) oppose each other at the surface, but reinforce each other at depth. In (b), the Ekman advection (white arrow) is included. From Lee and Williams (2000). 


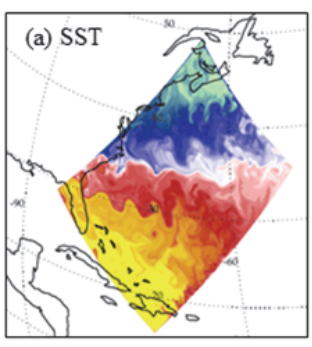

$\frac{\operatorname{SST}\left({ }^{\circ} \mathrm{C}\right)}{\text { 9. 11. 13. 15. 17. 19. 21. 23. }}$

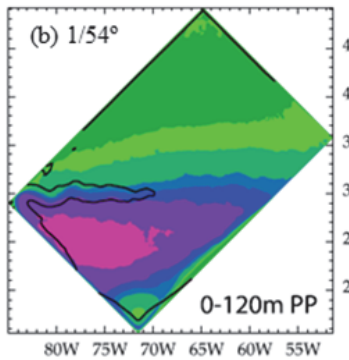

80W $75 \mathrm{~W}$ 70W $65 \mathrm{~W}$ 60W $55 \mathrm{~W}$

mmolN m ${ }^{-2} y^{-1}$
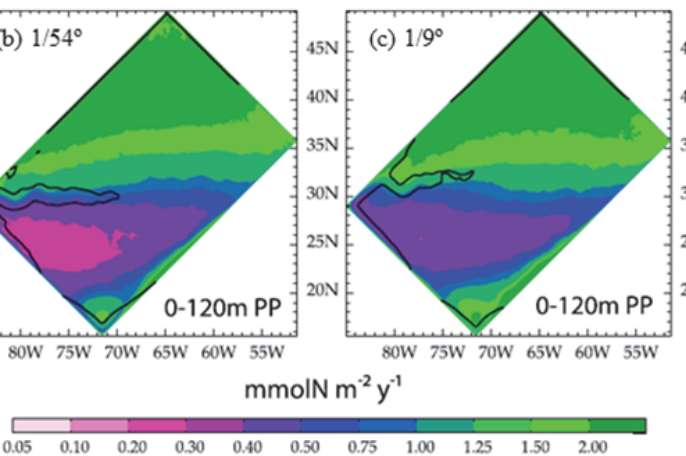

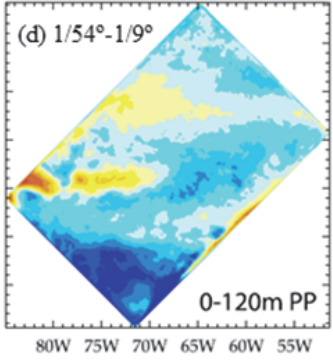

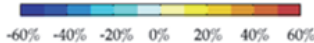

Figure 11. (a) Sea surface temperature simulated in an idealized double-gyre system of the western North Atlantic. Panels (b) and (c) show five-year average depth-integrated (0-120m) primary production for $1 / 54^{\circ}$ and $1 / 9^{\circ}$ models after 50 years of integration; panel (d) shows their difference. Note the different map projection in panel (a) from Lévy and Martin (2013) versus panels (b-d) from Lévy et al. (2012b). 
(a)

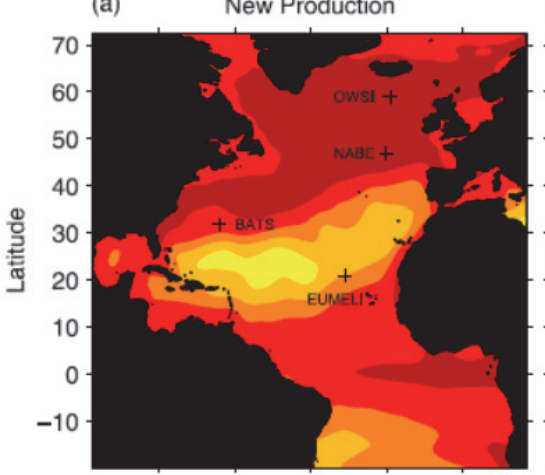

(c) Total Vertical Advection

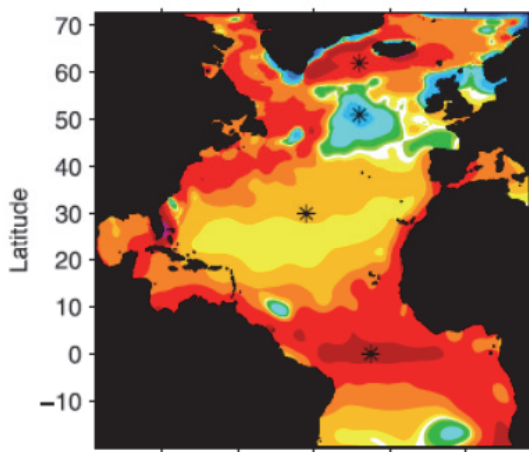

(f) Total Horizontal Advection

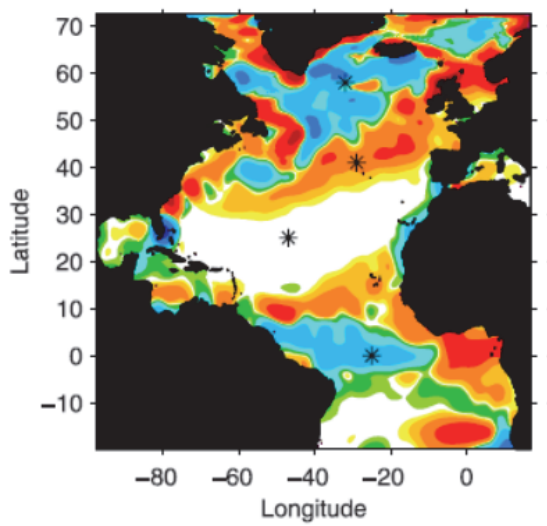

(b) Convection \& Vertical Diffusion

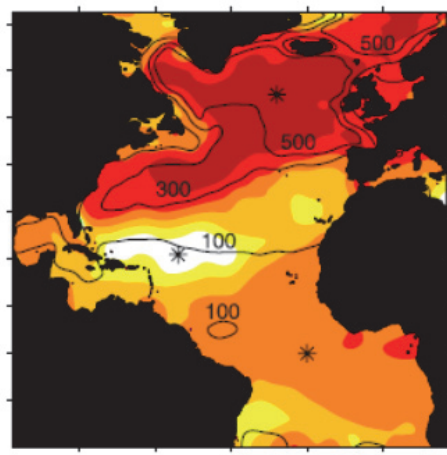

(d) Mean Vertical Advection

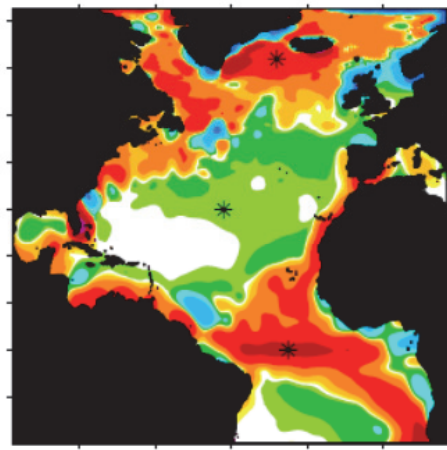

(g) Mean Horizontal Advection

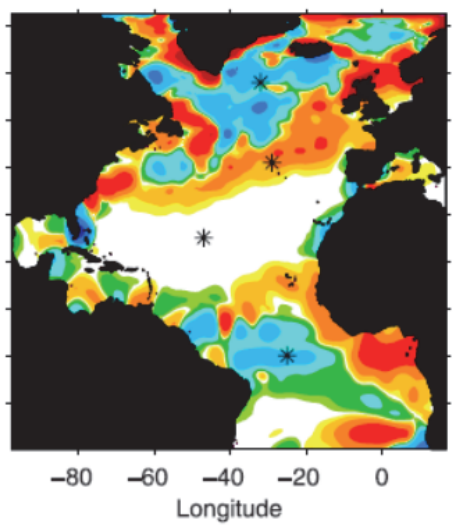

Run $13 e$

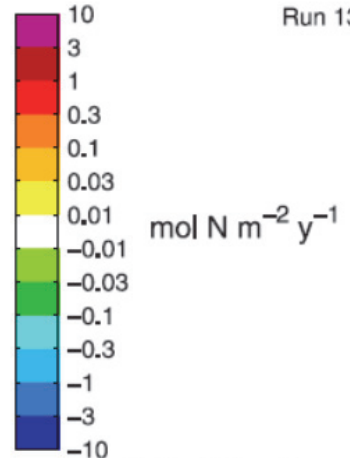

(e)

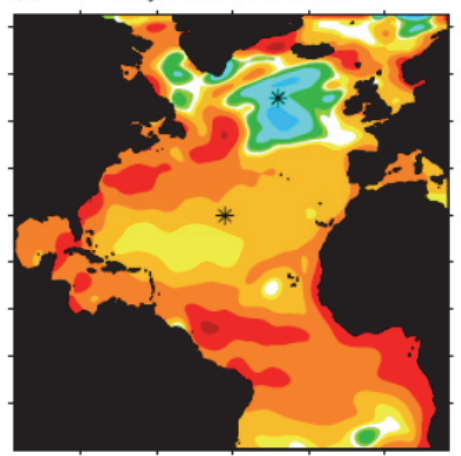

(h) Eddy Horizontal Advection

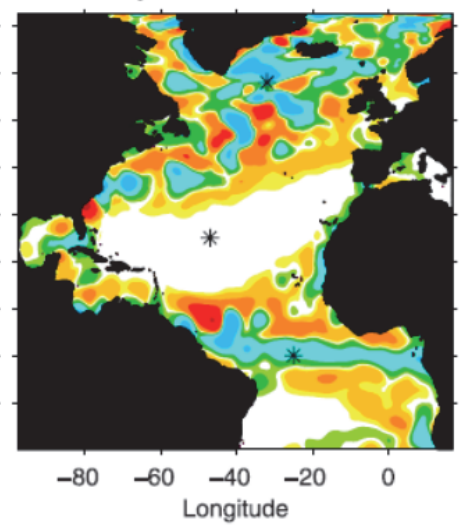

Figure 12. Five-year time-averaged new production (a) and nutrient supply terms (b-h), integrated over the euphotic zone. Advective fluxes in the vertical (middle row) and horizontal (lower row) have been separated into their mean and eddying components. All fields have been smoothed with a 24-point e-folding scale Gaussian filter. Asterisks indicate the main features of the solutions described in the text. Contours in Figure panel (b) indicate maximum wintertime mixed layer depths of 100,300 , and $500 \mathrm{~m}$. Note that wintertime mixed layers inside the $500-\mathrm{m}$ contour exceed that value by severalfold; additional contours are not shown for clarity of presentation. From McGillicuddy et al. (2003). 
An Eddy-driven Nutrient Sink:

Mesoscale Restratification After Deep Convection

Figure 13. Schematic of the eddy-driven processes that tend to restratify an area of deep convection in the open ocean. Inward flux near the surface and outward flux at depth imply a downward eddy-driven transport that removes nutrients from the euphotic zone. Note that the convective area does not represent an individual chimney but the larger region over which mesoscale and submesoscale convective events take place. From McGillicuddy et al. (2003).

1413

1414

1415

1416 

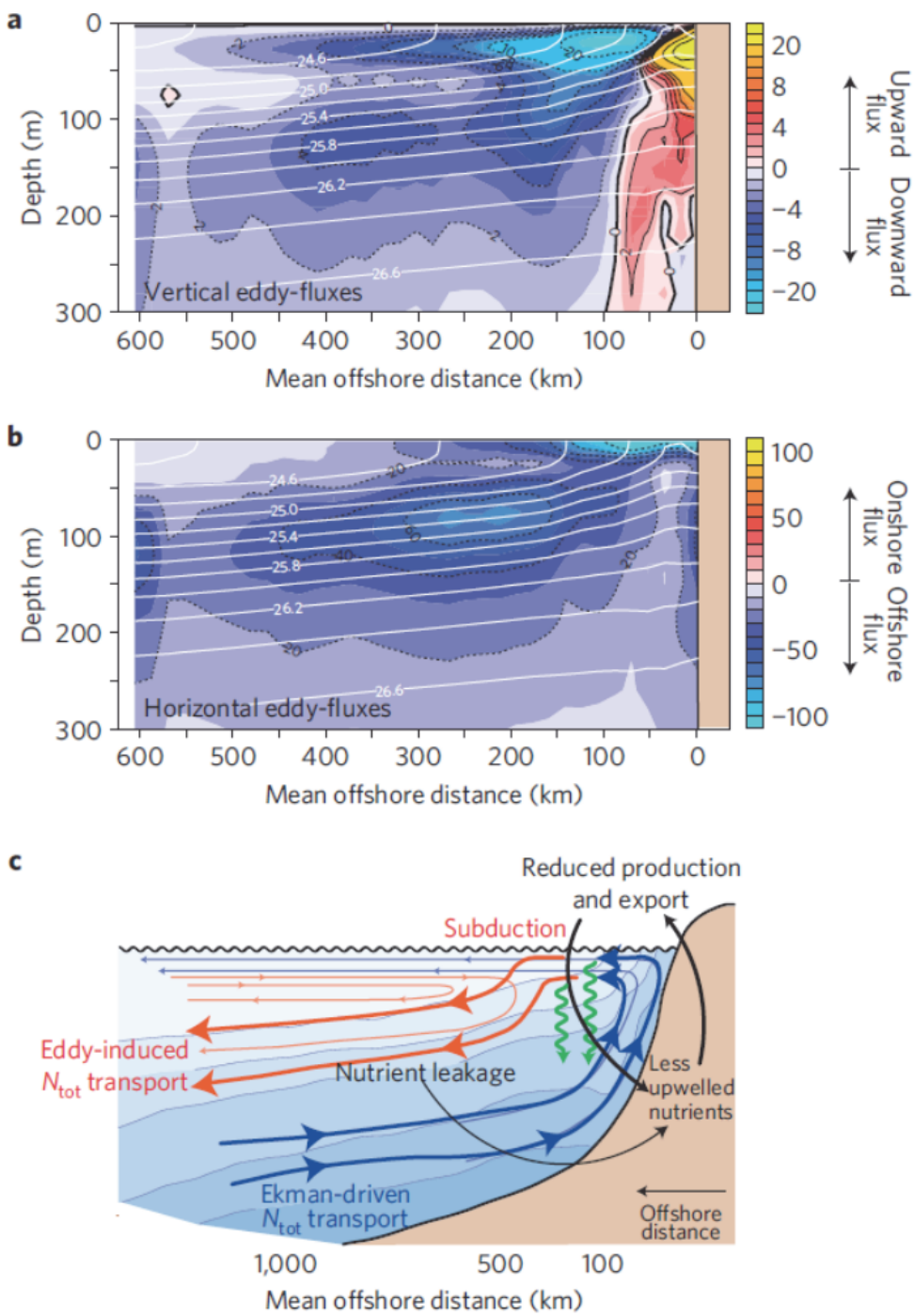

Figure 14. Cross-shore sections illustrating the role of eddies in inducing a lateral loss of total 1419 nitrogen from a model of the California Current system. Panels (a) and (b) depict vertical and 1420 horizontal fluxes of total nitrogen, respectively; units are nmol m $\mathrm{m}^{-2}$. White lines are potential density; black dashed lines indicate negative fluxes. Panel (c) depicts a conceptual diagram of the impact of mesoscale eddies on coastal circulation, nitrogen transport, and organic matter production and export. The thick lines indicate total nitrogen transports and the thin lines depict circulation pattern. Shown in blue are the Ekman-driven transports and circulations. The red arrows show the eddy-driven transports. Contour lines denote potential density and green arrows the vertical export of organic matter. From Gruber et al. (2011). 

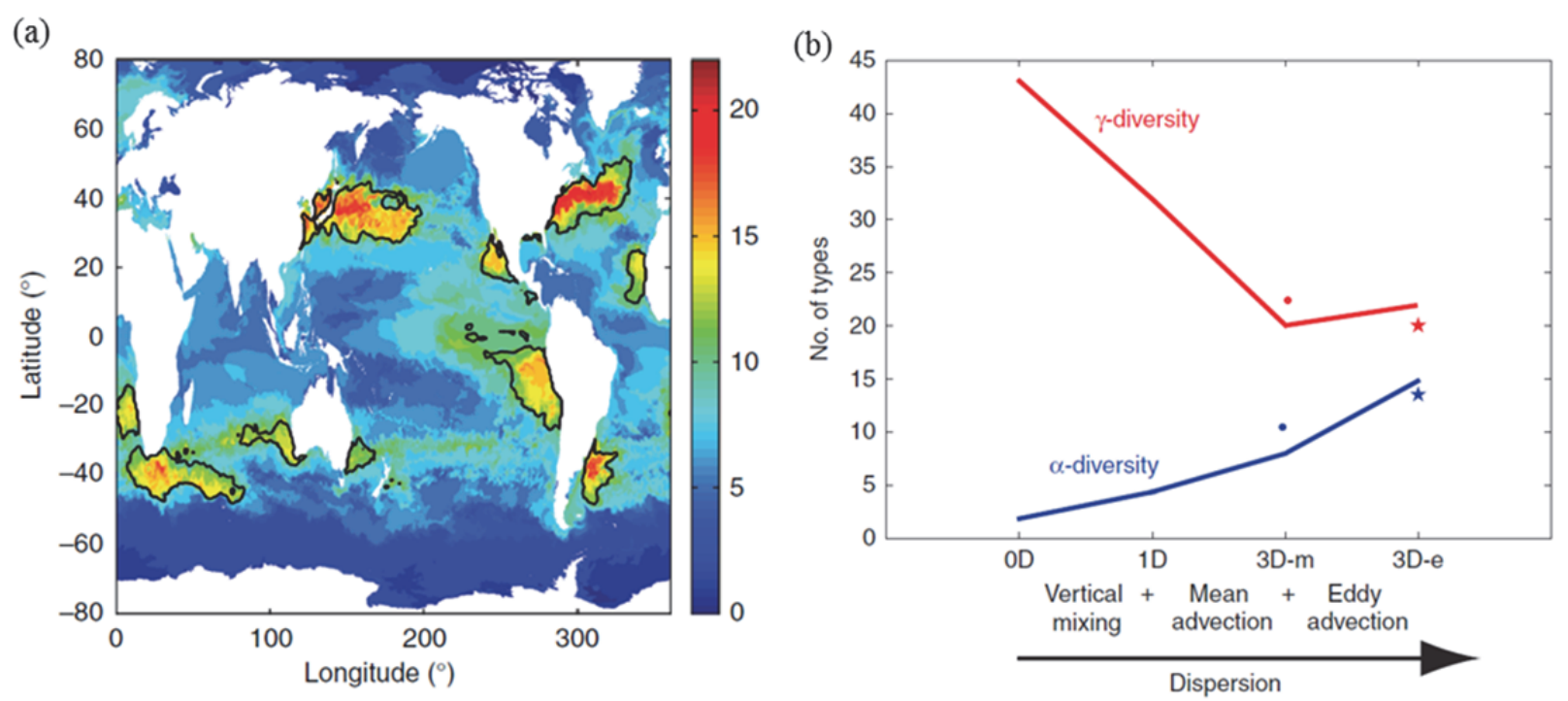

Figure 15. (a) Annual average diversity in the surface layer of the high-resolution (HR) configuration described in Clayton et al. (2013). Diversity $(\alpha)$ is defined as the total number of phytoplankton types with biomass greater than $0.001 \%$ of the total phytoplankton biomass. Black 1433 contour lines indicate phytoplankton diversity hotspots $(\alpha>10.2)$. (b) Trends in local diversity $1434(\alpha ; 10-100 \mathrm{~km}$ scales $)$ and regional diversity $(\gamma ; 1000 \mathrm{~km}$ scales $)$ as a function of dispersion from the simulations described in Lévy et al. (2014). Experiments 0D, 1D, 3D-m, and 3D-e are ranked along the $\mathrm{x}$-axis by increasing level of dispersion in the flow field. In the case with no dispersion (0D) each grid cell in the horizontal and vertical dimensions is treated independently. Vertical mixing is added in the 1D case, and advection by the mean velocity is added in the 3D$\mathrm{m}$ case. The full eddy-resolving flow is accounted for in 3D-e. Results from the latter two experiments are marked with dots and stars, respectively. 